\title{
Evaluating the Techno-economic Potential of an Integrated Material Recovery and Waste-to-Hydrogen System
}

\author{
Kok Siew Nga,", Anh N. Phan ${ }^{b}$ \\ ${ }^{\text {a }}$ Department of Engineering Science, University of Oxford, Parks Road, Oxford OX1 3PJ, United Kingdom. \\ ${ }^{\mathrm{b}}$ School of Engineering, Newcastle University, Newcastle upon Tyne NE1 7RU, United Kingdom.
}

\section{Abstract}

This study proposes a novel integrated material recovery and waste-to-hydrogen concept in view of enhancing resource efficiency and minimising environmental impact. A comprehensive techno-economic evaluation is conducted on an integrated system consisting of material recovery facility (MRF) and gasification of rejected materials for hydrogen production (Gasification- $\mathrm{H}_{2}$ ). Valorising these rejected materials through Gasification- $\mathrm{H}_{2}$ system can 2 potentially offer a saving of 1.6 million $£ / y$ on disposal cost while diverting significant amount 3 of waste from landfills. Owing to the high market value of hydrogen, the integrated system 4 with material recovery and hydrogen production generates 4 times more revenues than a 5 conventional MRF, though at the expense of higher capital and operating costs. The minimum 6 hydrogen selling price lies in the range of $2.2 £ / \mathrm{kg}$ (100 dry t/h of rejects) and $6.1 £ / \mathrm{kg}$ (2 dry $7 \mathrm{t} / \mathrm{h}$ of rejects). This study concludes that a larger Gasification- $\mathrm{H}_{2}$ system is desirable, i.e. greater 8 than 100 dry $\mathrm{t} / \mathrm{h}$ of rejects, to compete with the production cost of hydrogen generated from 9 fossil-based systems. It is also recommended that an economically competitive production 20 should comprise multiple MRF integrated with a large-scale Gasification- $\mathrm{H}_{2}$ system.

1 Keywords: Resource recovery; waste-to-hydrogen; polygeneration; recycling; circular 22 economy; gasification.

* Corresponding author. Email: kok.ng@eng.ox.ac.uk; Tel: +44(0)7919 074975 (KS Ng) 


\section{Introduction}

2 Household recycling waste is collected by local authorities in the UK and is subsequently sent

3 to material recovery facilities (MRF), which consist of a series of mechanical sorting and

4 screening processes for recovery of marketable products such as paper and card, glass, metals

5 and plastics. So far, MRF is the preferred method of treating recycling stream in view of

6 recovering value from waste while diverting waste from landfills [1]. There are a number of

7 challenges in achieving maximum resource recovery from waste using an MRF. Firstly, segregation of waste at source has its own limitation due to the lack of awareness of local residents and confusion over which materials can be recycled $[2,3]$. This results in generation of commingled or contaminated recycling waste streams and creates a significant portion of non-recyclable materials (also referred to as "rejects"). The non-recyclable materials in this context include materials that cannot be reprocessed and those which may cause damage to the sorting equipment. These will need to be sent to energy-from-waste (EfW) facilities and landfills according to the conventional waste management approach. Based on the findings reported in the existing literature, the reject rate (i.e. amount of non-recyclable materials with respect to the amount of incoming recycling waste stream into MRF) is typically 6-8\% and can reach up to $27 \%[2,3]$. Secondly, MRF has its inherent technological constraints in terms of coping with highly contaminated waste streams [4]. Additional equipment needs to be installed or operating conditions need to be altered if the composition of the incoming materials varies significantly. The removal of contaminants prior to MRF and quality control during sorting are labour-intensive processes, leading to higher processing costs [5]. Therefore, it is imperative to explore alternatives that can handle the rejected stream from MRFs.

The rejected material stream generated from mechanical treatment processes in MRF (i.e. shredding and sorting) can be converted into refuse derived fuel (RDF) or solid recovered fuel (SDF) [6]. RDF/SDF has high net calorific values ( 15-25 MJ/kg or even higher [7]) and suitable for use as a fuel in cement kiln industry and combustion/gasification plants. SDF, typically derived from commercial and industrial $(\mathrm{C} \& \mathrm{I})$ waste, is a more refined fuel compared to RDF which derived from municipal solid waste (MSW). A number of studies have demonstrated the application of RDF/SDF in thermal conversion technologies such as gasification [8-10], torrefaction or carbonisation [11-13] and pyrolysis [14, 15] for energy generation. Furthermore, there are also a number of studies $[2,16,17]$ that recommend the concept of integrating MRF and energy recovery through EfW to improve resource utilisation. However, it remains debatable whether EfW and the application of RDF in heat and electricity 
1 (i.e. low value products) generation should be considered as sustainable waste management 2 options [6].

3 The rejected materials from MRF can potentially be valorised into higher value products such 4 as fuels and chemicals. Some examples are polyhydroxybutyrate (PHB) production from the cellulosic fraction of organic residuals [18] and methanol production from gasification of RDF

6 [19]. The life cycle assessment conducted by Kendall [18] shows that the energy consumption and greenhouse gas emissions of using organic residuals from MRF for PHB production are twice lower than using agricultural feedstock such as corn. Borgogna et al. [19] investigated the effect of variability of RDF composition on gasification performance (i.e. syngas quality and composition) and methanol production (i.e. yield, raw material and energy consumptions and emissions). These studies have mainly focused on the technical and environmental aspects of reject valorisation system, without considering a systems perspective which takes into account the impact from the upstream MRF process. The studies conducted by Cimpan et al. [20] and Pressley et al. [21] provide comprehensive techno-economic and life cycle assessments of conventional MRF. It has been shown that the high disposal cost of reject materials poses a significant impact on the revenue of MRF [20]. Hence, there is a strong motivation to avoid the high disposal cost through utilisation of reject materials for value-added production. Overall, there are limited studies on the valorisation pathways of MRF rejected materials and none of these studies have included a comprehensive techno-economic assessment to justify the feasibility and potential of these valorisation pathways. Hydrogen has a wide application in the industry and has the potential to become an important energy carrier and clean fuel for the future [22, 23]. At present, hydrogen is primarily produced from steam reforming of natural gas. The renewable source of hydrogen (e.g. electrolysis of water) is limited mainly due to the cost barriers that is less competitive with fossil based hydrogen from steam reforming of natural gas or coal gasification [24]. Waste-to-hydrogen concept [25-27] is gradually receiving more attention in view of its environmental benefits through replacing fossil-based transportation fuels while contributing towards net zero emission target. Production of hydrogen from gasification of biomass [28, 29] and MSW [30, 31] has been demonstrated in various studies. A review conducted by Shahabuddin et al. [26] report that the production cost of hydrogen from residual waste lies in the range of 1.4-4.8 USD/kg compared to biomass of 2.3-5.2 USD/kg, depending on the gate fees and plant scale. To date, the knowledge related to techno-economic feasibility of gasification of MRF reject materials for hydrogen production has not been developed. 
1 Sustainable waste management through deploying a more robust and resilient facility which encompasses resource recovery and valorisation strategies [32, 33] is needed to treat the contaminated and rejected waste stream from MRF. Introducing an additional valorisation system into an existing MRF will inevitably increase the processing costs. Adopting polygeneration strategies in system design (i.e. simultaneous generation of energy/fuels/chemicals/materials in an integrated system) would enhance resource efficiency, leading to an economically competitive production [34-36]. A system-wide understanding on the techno-economic viability of integrating MRF and reject valorisation system is currently lacking. This study, for the first time, proposes a novel integrated system consisting of an MRF for material recovery and gasification for hydrogen ("Gasification- $\mathrm{H}_{2}$ ") production. This research aims to address the gaps of knowledge by conducting a comprehensive technoeconomic assessment to explore the future potential of implementing this kind of integrated system. The novelty of this research lies in the proposition of an integrated material recovery and valorisation system using polygeneration strategy which enhances resource efficiency and diverts waste from landfills and incineration. Figure 1(a) shows a conventional recycling approach using MRF and Figure 1(b) shows an integrated MRF and valorisation system. The ultimate goal is to shift from selective recycling (i.e. material recovery through separating specific types of recyclable materials) model into an "omnivorous" recycling (i.e. integrated material recovery of recyclable stream and valorisation of non-recyclable stream) model. The objectives of this study are to (a) establish a conceptual process design and modelling framework; (b) evaluate economic feasibility; and (c) identify strategies for improving the integrated MRF and Gasification- $\mathrm{H}_{2}$ system. This paper is structured as follows. The methodology for conceptual design and techno-economic assessment is presented in Section 2. Process modelling of conventional MRF and integrated MRF and Gasification- $\mathrm{H}_{2}$ systems is presented in Section 3, followed by economic assessment presented in Section 4. Conclusions and recommendations of the study are presented in Section 5. 
Mixed recyclables

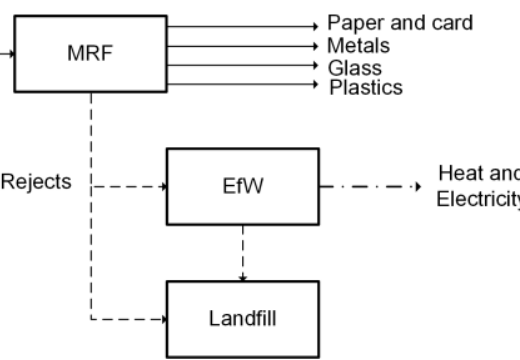

(a)

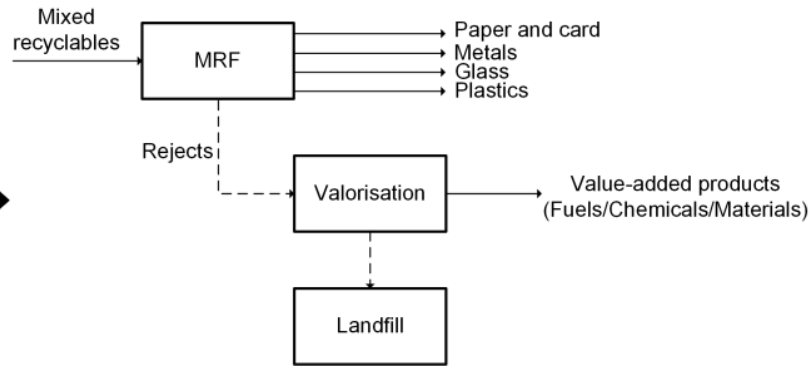

(b)

Figure 1: (a) Conventional approach to mixed recyclable management. (b) Proposed integrated MRF and valorisation of mixed recyclable stream.

\section{Methodology}

This section provides an overview of the methodology (section 2.1), followed by detailed discussion on each stage of techno-economic assessment, including data collection (section 2.2), conceptual design (section 2.3), economic analysis (section 2.4) and scenario analysis (section 2.5).

\subsection{Overview of the methodology}

A systematic methodology [37, 38] was adopted for conducting techno-economic analysis on an integrated MRF and Gasification- $\mathrm{H}_{2}$ system as illustrated in Figure 2. Flow and composition data of feedstock as well as system performance and cost data were collected at the outset. These data were used to establish the technical model in the conceptual design stage and economic model in the economic analysis stage. In the conceptual design stage, flowsheet models of the system were constructed and validated against the results published in literature. Material and energy balances in conjunction with energy integration were performed to determine the yield of primary products, the quantity of rejected materials generated and energy requirement of the systems under consideration. The results from material and energy balances (conceptual design stage) alongside the system performance and cost data (data collection stage) were inputted into the economic model which consists of capital and operating costs evaluation and profitability analysis. Scenario analysis was carried out to investigate the impact of varying operating parameters of MRF (i.e. separation efficiency) and Gasification- $\mathrm{H}_{2}$ system (i.e. throughput of rejected materials) on the economic performance of the systems. The findings generated from economic analysis and scenario analysis were concluded, accompanied by recommendations for further improvement of the systems. 


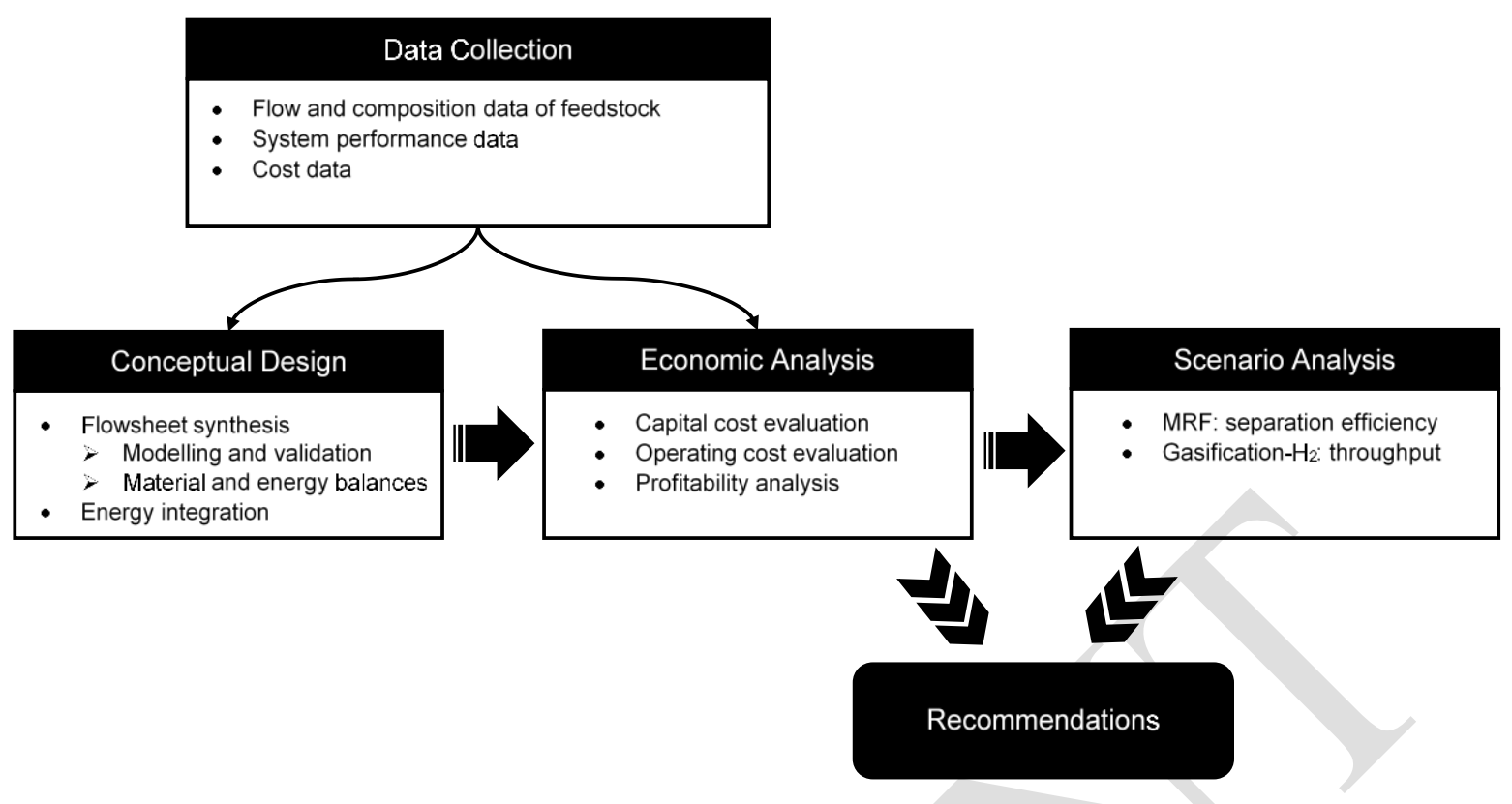

1

2 Figure 2: Techno-economic analysis of integrated MRF and Gasification- $\mathrm{H}_{2}$ system.

\subsection{Data collection}

The flow and composition data for household recycling streams in the UK were collected from the WRAP National Household Waste Composition 2017 report [39]. In the present analysis,

the data and waste categories were refined to include only the waste component relevant to mixed recyclables, i.e. any food and garden wastes were excluded. The household recycling waste streams include segregated waste from kerbsides, Household Waste Recycling Centres (HWRC), bring sites, street bins and "other means".

System performance data such as separation efficiencies of sorting/screening equipment in 2 MRF were collected from Pressley et al. [21], and operating parameters of process units in 3 Gasification- $\mathrm{H}_{2}$ system were obtained from the National Renewable Energy Laboratory 4 (NREL) report [28].

5 For MRF, equipment and variable operating cost data were collected from Pressley et al. [21] 6 and WRAP report [40]. On the other hand, the equipment and variable operating cost data for 7 Gasification- $\mathrm{H}_{2}$ system were adopted from Sadhukhan et al. [38] and NREL report [28]. Lang 8 factors for capital cost estimation and typical factors used for fixed operating cost estimation 9 were obtained from Sadhukhan et al. [38]. The most recent gate fees for landfill and EfW and 0 market prices of recyclable products from MRF were obtained from LetsRecycle.com. 


\subsection{Conceptual design}

2 This section discusses the methodology for flowsheet synthesis (section 2.3.1) and energy

3 integration (section 2.3.2).

\subsubsection{Flowsheet synthesis}

The configuration of MRF in the present study was inspired by the works conducted by WRAP [40] and Pressley et al. [21], while the configuration of Gasification- $\mathrm{H}_{2}$ system was adapted from NREL study [28]. In practice, the unit operations in MRF and gasification can be arranged in various configurations. The main processing steps in these systems were outlined using block diagrams, and information on systems performance such as separation efficiencies and operating conditions of process units were collected from published journal articles and technical reports, discussed in section 2.2. The current flowsheeting approach adopts a generic structure to model changes in flow and composition of materials and also energy consumption and generation. This reduces the complexity of the system configuration while ensuring important features to be captured. The flowsheets were simplified to include only the primary processing steps. Multiple separation stages for recovering same category of materials in MRF were represented as a single block (i.e. paper/card, metal, glass and plastics separation). Manual sorting in different stages was also taken as one unit operation in MRF. In the gasification system, all the auxiliary equipment such as valves and storage tanks was eliminated from the flowsheet during the conceptual design stage. The throughput of rejected materials entering the Gasification- $\mathrm{H}_{2}$ system was deduced from the MRF model. The modelling of MRF was carried out in Excel environment. In the case of Gasification- $\mathrm{H}_{2}$ system where more sophisticated reaction-separation processes were involved, simulation modelling approach using Aspen Plus software, a widely used process engineering software in the refinery and petrochemical industries, was adopted. The flowsheets were constructed by adopting an evolutionary approach where simulation models / blocks were introduced starting from reactors, then separators, and finally heat exchangers and utility systems according to the "onion" model for process design [41]. The simulation models of unit operations, particularly the gasification model, were validated against published experimental results [30]. The flowsheet synthesis exercise enables material and energy balances of the conventional MRF and integrated MRF and Gasification- $\mathrm{H}_{2}$ systems to be established prior to detailed techno-economic analysis. 


\subsubsection{Energy integration}

2 Systematic energy integration [37, 38] was performed on Gasification- $\mathrm{H}_{2}$ system in view of 3 enhancing energy efficiency of the system (Note: this has not been done on MRF since there

4 is limited scope for energy recovery within MRF. The system only requires input of electricity).

5 Energy integration strategies adopted here began with data extraction, followed by 6 classification of energy integration tasks, and a combined heat and power (CHP) network 7 design. Data extraction involved collection of temperature and heat duty information of heat exchangers and process units from the flowsheet. By examining the level of temperature and heat duties, these data were then classified into high and low level energy integration tasks. High level tasks refer to steam generation and consumption at different pressures, analysed using composite curve methodology. Low level tasks refer to process-to-process heat exchange and boiler feed water generation, analysed using energy balance. This stream classification procedure maximises opportunities for energy recovery and enables appropriate placement of utilities. Finally, the CHP network was designed by considering steam and power generation and distribution within the Gasification- $\mathrm{H}_{2}$ system to ensure that all energy supply and demands are satisfied.

\subsection{Economic analysis}

The economic performances of MRF and Gasification- $\mathrm{H}_{2}$ systems were evaluated in terms of capital costs (section 2.4.1), operating costs (section 2.4.2) and profitability analysis (section 2.4.3).

\subsubsection{Capital cost evaluation}

Equation (1) [37, 38] was applied to estimate the purchased costs of equipment for the current system by using the capacity and cost data of the base system reported in the literature.

$25 \frac{\operatorname{COST}_{\text {size } 2}}{\operatorname{COST}_{\text {size } 1}}=\left(\frac{\mathrm{SIZE}_{2}}{\mathrm{SIZE}_{1}}\right)^{R}$

26 where

$27 \mathrm{SIZE}_{1}$ is the capacity of the base system,

$28 \mathrm{SIZE}_{2}$ is the capacity of the system after scaling up/down, 
$1 \operatorname{COST}_{\text {sizel } 1}$ is the cost of the base system,

$2 \operatorname{COST}_{\text {size } 2}$ is the cost of the system after scaling up/down,

$3 \quad R$ is the scaling factor.

4

5 The purchased costs of equipment estimated using Equation (1) were levelised to the present 6 year using Equation (2) [37, 38] by applying the Chemical Engineering Plant Cost Index 7 (CEPCI).

$9 \quad C_{p}=C_{o}\left(\frac{I_{p}}{I_{o}}\right)$

10 where

$11 C_{p}$ is the present cost of equipment,

$12 C_{o}$ is the original cost of equipment,

$13 I_{p}$ is the present index value,

$14 I_{o}$ is the original index value.

15 The total purchased costs of equipment estimated using Equations (1)-(2) were multiplied by 16 Lang factors to obtain the total capital cost (TCC) of the system. TCC includes direct costs 17 (installation, instrumentation and control, piping, electrical systems, building, yard 18 improvements and service facilities), indirect costs (engineering and supervision, construction 19 expenses, legal expenses, contractors' fees and contingency) and working capital.

20 Annualised capital costs $\left(C_{c a p}\right)$ of the system was determined by multiplying $T C C$ with capital 21 recovery factor $(C R F)$, shown in Equation (3) [42].

$23 C R F$, defined in Equation (4), converts present value (TCC is the present value in this context) 24 to annual payment over $n$ years (i.e. plant life) at a specified discount rate of $r$ [42].

$25 \quad C R F=\frac{r(1+r)^{n}}{(1+r)^{n}-1}$ 
2 Operating costs $\left(C_{o p}\right)$ include fixed (e.g. maintenance, capital charges, insurance, local taxes, 3 royalties, laboratory costs, supervision and plant overheads) and variable (e.g. fuel, electricity, 4 baling wire and catalyst) costs. Fixed operating costs were estimated based on percentage of 5 indirect capital cost or cost of personnel. Variable operating costs were estimated using the 6 latest available price data from published sources.

7

\subsubsection{Profitability analysis}

9 The economic performance of the systems was analysed using economic potential (EP) 10 expressed by Equation (5) and minimum hydrogen selling price (MHSP) expressed by 11 Equation (6) [38]. The EP indicates the difference between the revenues generated from the 12 sale of products and the associated costs of production. In the context of MRF, the cost of feed 13 (i.e. mixed recyclables) was assumed to be zero.

$14 \mathrm{EP}=$ Value of products $-($ Cost of feed + Annualised capital cost + Operating cost $)$

MHSP is not relevant to MRF case as the value of products is determined by the recycling market. However, this indicator is particularly useful for evaluating minimum value of hydrogen from the Gasification- $\mathrm{H}_{2}$ system. MHSP indicates the minimum value of hydrogen where the market price of hydrogen must be higher than MHSP to result in an economically feasible processing scenario.

MHSP $=\frac{(\text { Cost of feed }+ \text { Annualised capital cost }+ \text { Operating cost })}{\text { Production rate of hydrogen }}$

\subsection{Scenario analysis}

In this study, two scenarios were examined: (a) enhancing separation efficiency of MRF sorting/screening processes; and (b) increasing throughput of MRF rejected materials into Gasification- $\mathrm{H}_{2}$ system. The impact on the economic performance of the system due to variation of the operating parameters were assessed. 
2 The basis for feedstock is given in section 3.1. The process description together with material 3 and energy balances for the conventional MRF and integrated MRF and Gasification- $\mathrm{H}_{2}$ system 4 are presented in sections 3.2 and 3.3, respectively.

5

6 The throughput of mixed recyclables into MRF was 100,000 t/y (18.5 t/h considering 5400 7 operating hours per year) in the present study. The composition of mixed recyclable stream was refined based on the UK data from WRAP National Household Waste Composition 2017 report [3] (see Table A.1 in the Supplementary Materials, Appendix A) and was categorised into recyclable and non-recyclable fractions as presented in Table 1. The recyclable and nonrecyclable fractions for each waste category were deduced using the same ratio as in the study conducted by Pressley et al. [21] since it is not given in the original dataset. In this study, only polyethylene terephthalate (PET) bottles, high-density polyethylene (HDPE) bottles and mixed rigid plastics (i.e. dense plastics non-bottles and plastic film and bags) were considered as recyclable plastics, i.e. other types of plastic materials were classified as non-recyclables.

Table 1: Mass flow and composition of mixed recyclable stream for a 100,000 t/y MRF.

\begin{tabular}{|l|l|c|c|}
\hline \multicolumn{1}{|c|}{ Waste category } & Waste component & Mass fraction (\%) & Mass flow (t/h) \\
\hline Paper and card & Paper and card & 49.90 & 9.24 \\
\hline & Non-recyclable & 1.99 & 0.37 \\
\hline Metal & & & 1.13 \\
\hline & Ferrous metals & 6.11 & 0.49 \\
\hline & Aluminium metals & 2.64 & 0.26 \\
\hline & Non-recyclable & 1.40 & 4.60 \\
\hline Glass & & & 0.08 \\
\hline & Glass & 24.84 & 0.54 \\
\hline & Non-recyclable & 0.43 & 0.27 \\
\hline Plastics & & & 0.66 \\
\hline & PET bottles & 2.90 & 0.28 \\
\hline & HDPE bottles & 1.45 & \\
\hline & Mixed rigid plastics & 3.58 & 0.60 \\
\hline & Non-recyclable & 1.52 & $\mathbf{1 8 . 5 2}$ \\
\hline Other materials & & & \\
\hline & Organics and inorganics & 3.24 & $\mathbf{1 0 0 . 0 0}$ \\
\hline & \multicolumn{1}{|c|}{ Total } & &
\end{tabular}

In the proposed integrated system, the rejected streams from MRF were sent to gasification for hydrogen production. It was assumed that the rejected streams were composed of only combustible materials (i.e. non-combustible materials such as metals and glass were 
1 completely removed prior to feeding into the gasifier). The proximate and ultimate analyses of the rejected materials from MRF are given in Table 2, which were adapted and normalised based on the original laboratory analysis [43]. Since the compositions of volatile matters and fixed carbon were not given, these values were assumed based on the MSW analysis from literature [30].

Table 2: Proximate and ultimate analyses of rejected materials from MRF (Adapted from [43] and [30]).

\begin{tabular}{|l|c|c|}
\hline \multicolumn{1}{|c|}{ Component } & Value & Unit \\
\hline Proximate analysis (as received) & & \\
\hline Volatile matter & 47.59 & $\mathrm{wt} \%$ \\
\hline Fixed carbon & 6.82 & $\mathrm{wt} \%$ \\
\hline Ash & 18.80 & $\mathrm{wt} \%$ \\
\hline Moisture content & 26.80 & $\mathrm{wt} \%$ \\
\hline & & \\
\hline Ultimate analysis (dry and ash free) & & \\
\hline C & 63.77 & $\mathrm{wt} \%$ \\
\hline H & 8.23 & $\mathrm{wt} \%$ \\
\hline O & 25.79 & $\mathrm{wt} \%$ \\
\hline N & 1.42 & $\mathrm{wt} \%$ \\
\hline S & 0.79 & $\mathrm{wt} \%$ \\
\hline Net calorific value (as received) & 12.0 & $\mathrm{MJ} / \mathrm{kg}$ \\
\hline Net calorific value (dry) & 16.8 & $\mathrm{MJ} / \mathrm{kg}$ \\
\hline
\end{tabular}

\subsection{Material Recovery Facility (MRF)}

9 The mechanical separation/sorting processes of mixed recyclable stream in MRF is described in section 3.2.1. The material and energy balances are presented in section 3.2.2.

\subsubsection{Process description}

12 A typical MRF as illustrated in Figure 3 consists of five separation/sorting stages for recovering recyclable materials such as paper/card, metals, glass and plastics into individual streams. Mixed recyclables are loaded onto a conveyor (stream 1: $18.5 \mathrm{t} / \mathrm{h}$ ) and manually sorted to separate recyclable materials from non-recyclable materials or materials which are not compliant with the MRF equipment. At the manual sorting stage, plastic films and bags (stream 2: $0.5 \mathrm{t} / \mathrm{h}$ ) are recovered through a vacuum, and then sent for baling. The recyclable materials (stream 3:17.7 t/h) which are separated from the rejects (stream 4: $0.28 \mathrm{t} / \mathrm{h}$ ) are sent to trommel and ballistic separator (paper/card separation stage). Trommel, a negative sorting process, is used to remove undesirable fine inert materials such as glass, mixed rigid plastics and organic materials (e.g. soil and aggregates). Ballistic separator, on the other hand, is used to separate heavy and light materials by oscillations. Light materials such as card and paper (stream 5: 8.4 
$1 \mathrm{t} / \mathrm{h}$ ) are recovered and baled, while heavy materials such as glass, cans and plastics (stream 6:

$2 \quad 7.9 \mathrm{t} / \mathrm{h}$ ) are transferred to magnet and eddy current separator (metal separation stage). Any

3 rejected materials (stream 7: $1.4 \mathrm{t} / \mathrm{h}$ ) from trommel and ballistic separator are removed from

4 the recyclable stream. At the metal separation stage, a magnet is used to separate metals from

5 glass. A further screening through an eddy current separator allows ferrous metals such as steel

6 cans (stream 8: $1.0 \mathrm{t} / \mathrm{h}$ ) to be split from non-ferrous metals such as aluminium cans (stream 9:

$7 \quad 0.4 \mathrm{t} / \mathrm{h}$ ). A non-metal stream comprising mainly glass (stream 10: $6.2 \mathrm{t} / \mathrm{h}$ ) is obtained after

8 rejecting non-recyclable materials (stream 11: $0.26 \mathrm{t} / \mathrm{h}$ ). The glass stream which is free from

9 metals is sent through an air classifier (also known as a "wind sifter" at the glass separation

10 stage) to recover glass (stream 12: $3.6 \mathrm{t} / \mathrm{h}$ ) which is then bailed. Air classifier separates denser

11 materials such as glass from lighter materials such as papers based on difference in densities.

12 A plastic-rich stream (stream 13: $1.5 \mathrm{t} / \mathrm{h}$ ) is obtained after eliminating light paper and other

13 contaminants (stream 14: 1.1 t/h). The plastic-rich stream is screened through a series of optical

14 or near infrared (NIR) sorters (plastic sorting stage), where the separation is operated based on

15 detection of the absorption of certain wavelengths that can be used to distinguish between

16 different polymers. In this design, a 3-stage NIR sorters is assumed to generate a PET bottle

17 stream (stream 15: $0.45 \mathrm{t} / \mathrm{h}$ ), a HDPE bottle stream (stream 16: $0.2 \mathrm{t} / \mathrm{h}$ ) and a mixed rigid

18 plastics stream (stream 17: $0.1 \mathrm{t} / \mathrm{h}$ ). These plastic streams (streams 2, 15, 16 and 17) are bailed

19 separately and sent to plastic reprocessing plants. The recycled products including card and

20 paper, metals and glass (streams 5, 8, 9 and 12) are delivered to the respective recycling centres

21 for further processing. The remaining non-recyclable materials including contaminated plastic

22 materials (stream 18: $0.7 \mathrm{t} / \mathrm{h}$ ) are rejected. The aggregation of residues (rejects) from each

23 sorting stage (stream 19: $3.8 \mathrm{t} / \mathrm{h}$ ) is sent to EfW and landfill. In this study, it is assumed that

$2490 \%(3.4 \mathrm{t} / \mathrm{h})$ of the rejects is sent to EfW while the remaining $10 \%(0.38 \mathrm{t} / \mathrm{h})$ is ended up in

25 landfill.

26 Material and energy balances of the MRF system are presented in section 3.2.2. 


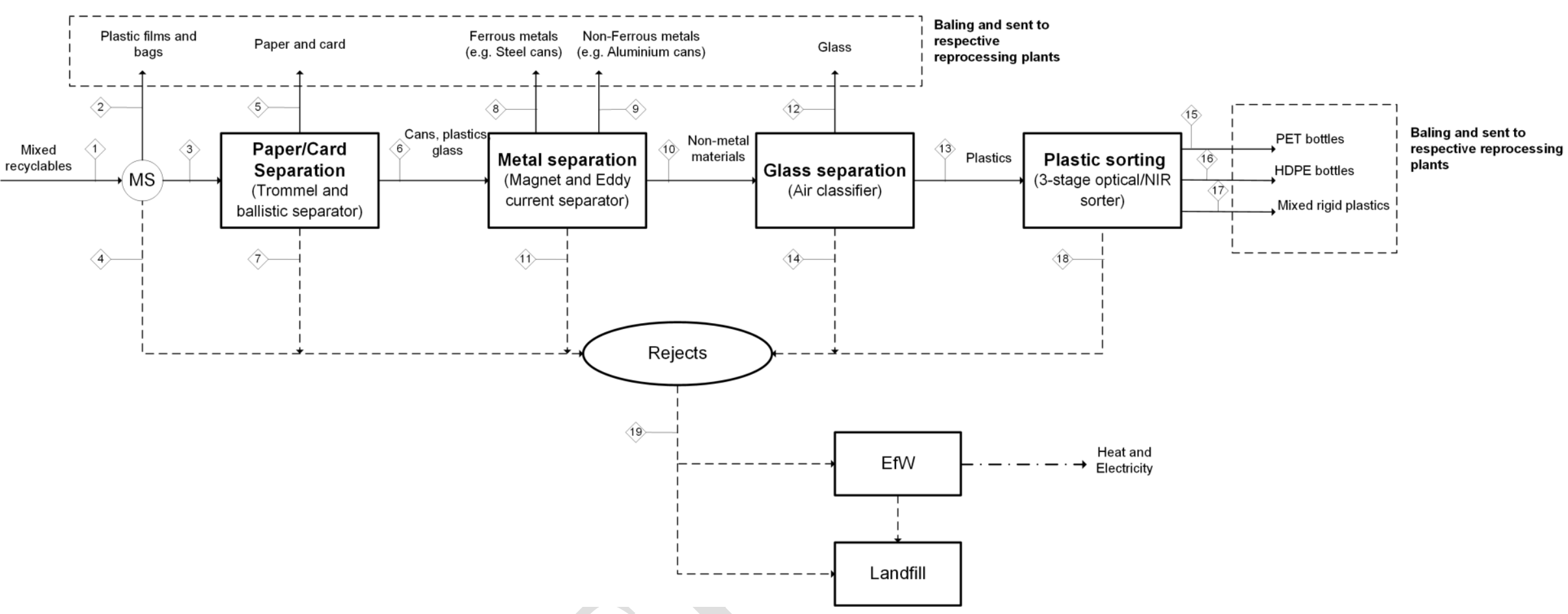

2 Figure 3: Material recovery facility (MRF) for separation and sorting of mixed recyclable stream. (MS: manual sorting; EfW: Energy-from-Waste facility; NIR: near infrared; 3 PET: polyethylene terephthalate; HDPE: high-density polyethylene) 
2 Table 3 presents the mass flow of mixed recyclable materials into MRF, the recyclable materials recovered from each separation stage, and the 3 discharge of non-recyclable materials from MRF. The material balance was deduced from the separation efficiencies presented in Table A.2 in the

4 Supplementary Materials (Appendix A), based on the study conducted by Pressley et al. [21]. A detailed breakdown of the input flow of individual 5 waste components into each stage is shown in Table A.3 in the Supplementary Materials (Appendix A).

6 Table 3: Material balance of MRF input and output materials for a 100,000 t/y MRF.

\begin{tabular}{|c|c|c|c|c|c|c|}
\hline \multirow[b]{2}{*}{$\begin{array}{c}\text { Separation } \\
\text { stages }\end{array}$} & \multicolumn{3}{|l|}{ Input } & \multicolumn{3}{|l|}{ Output } \\
\hline & Stream & $\begin{array}{l}\text { Stream } \\
\text { number }\end{array}$ & $\begin{array}{c}\text { Mass } \\
\text { flow } \\
(t / h) \\
\end{array}$ & Stream & $\begin{array}{l}\text { Stream } \\
\text { number }\end{array}$ & $\begin{array}{c}\text { Mass } \\
\text { flow } \\
(\mathrm{t} / \mathrm{h}) \\
\end{array}$ \\
\hline \multirow{4}{*}{$\begin{array}{c}\text { Manual } \\
\text { sorting }\end{array}$} & Mixed recyclables & 1 & 18.52 & Plastic films and bags & 2 & 0.54 \\
\hline & & & -2 & Materials entering paper/card separation stage & 3 & 17.70 \\
\hline & & 2 & +2 & Rejects & 4 & 0.28 \\
\hline & Subtotal & & 18.52 & Subtotal & & 18.52 \\
\hline \multirow{4}{*}{$\begin{array}{c}\text { Paper/card } \\
\text { separation }\end{array}$} & Materials entering paper/card separation stage & 3 & 17.70 & Paper and card & 5 & 8.41 \\
\hline & & + & & Materials entering metal separation stage & 6 & 7.89 \\
\hline & 2 & 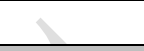 & -2 & Rejects & 7 & 1.40 \\
\hline & Subtotal & & $\mathbf{1 7 . 7 0}$ & Subtotal & & 17.70 \\
\hline \multirow{5}{*}{$\begin{array}{c}\text { Metal } \\
\text { separation }\end{array}$} & Materials entering metal separation stage & 6 & 7.89 & Ferrous metals & 8 & 1.00 \\
\hline & & + & 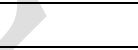 & Non-ferrous metals & 9 & 0.42 \\
\hline & 2 & + & & Materials entering glass separation stage & 10 & 6.21 \\
\hline & -2 & 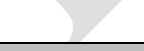 & & Rejects & 11 & 0.26 \\
\hline & Subtotal & & 7.89 & Subtotal & & 7.89 \\
\hline \multirow{4}{*}{$\begin{array}{c}\text { Glass } \\
\text { separation }\end{array}$} & Materials entering glass separation stage & 10 & 6.21 & Glass & 12 & 3.60 \\
\hline & 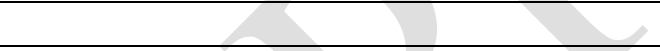 & & & Materials entering plastic sorting stage & 13 & 1.46 \\
\hline & 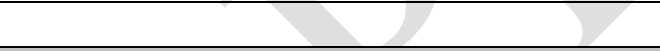 & & & Rejects & 14 & 1.14 \\
\hline & Subtotal & & 6.21 & Subtotal & & 6.21 \\
\hline \multirow{4}{*}{$\begin{array}{l}\text { Plastic } \\
\text { sorting }\end{array}$} & Materials entering plastic sorting stage & 13 & 1.46 & PET bottles & 15 & 0.45 \\
\hline & 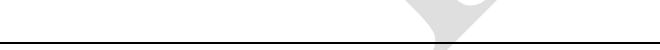 & & & HDPE bottles & 16 & 0.22 \\
\hline & +7 & & & Mixed rigid plastics & 17 & 0.10 \\
\hline & & & & Rejects & 18 & 0.70 \\
\hline
\end{tabular}




\begin{tabular}{|c|c|c|c|c|}
\hline Subtotal & 1.46 & Subtotal & & 1.46 \\
\hline Total input & 18.52 & Total output & & 18.52 \\
\hline & & Total rejects & 19 & 3.78 \\
\hline & & Total plastic materials to be recycled & $2+15+16+17$ & 1.31 \\
\hline & & Total non-plastic materials to be recycled & $5+8+9+12$ & 13.43 \\
\hline
\end{tabular}

2 Based on the material balance, approximately $80 \%$ of the input materials to MRF are recovered as recycled products (91\% non-plastics and $9 \%$ 3 plastics), while 20\% non-recyclable materials are rejected to EfW and landfill. A breakdown of the rejected material stream (stream 19) is 4 summarised in Table 4 together with the assumed components embedded in the stream. The rate of rejects falls within $27 \%$ reported by WRAP in 5 2012/2013 [3]. In this study, the main source of rejected materials are emerged from paper/card (37\%) and glass (30\%) separation stages.

6 Table 4: Breakdown of rejected material stream from each MRF separation stage.

\begin{tabular}{|c|c|c|c|}
\hline Separation stage & Rejected materials & $\begin{array}{c}\text { Contribution from } \\
\text { each stage } \\
\text { (wt \%) }\end{array}$ & Mass flow (t/h) \\
\hline Manual sorting & non-recyclable plastics & 7.44 & 0.28 \\
\hline Paper/card separation & non-recyclable papers and cards; glass; mixed rigid plastic; other materials. & 37.15 & 1.40 \\
\hline Metal separation & non-recyclable metals & 6.86 & 0.26 \\
\hline Glass separation & papers and cards; ferrous metals; aluminium metals; non-recyclable glass; other materials & 30.16 & 1.14 \\
\hline Plastic sorting & glass; contaminated PET bottles, HDPE bottles and mixed rigid plastics & 18.39 & 0.70 \\
\hline \multicolumn{2}{|r|}{ ( } & 100.00 & 3.78 \\
\hline
\end{tabular}

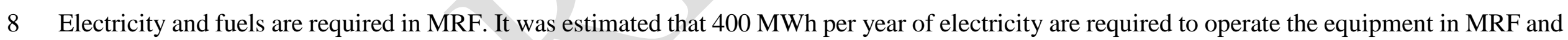

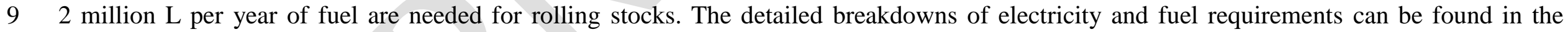

10 Supplementary Materials (Appendix A), Tables A.13-14 in conjunction with the cost estimation. 


\subsection{Integrated MRF and Gasification- $\mathrm{H}_{2}$ system}

2 The integrated system consisting of MRF and gasification of MRF rejected materials for 3 hydrogen production is described in section 3.3.1. The material and energy balances are 4 presented in section 3.3.2.

5

6 7

\subsubsection{Process description}

The rejected materials from MRF (stream 19) are valorised into hydrogen through a steam gasification system as illustrated in Figure 4. The system was modelled using Aspen Plus simulation software where the flowsheet and process description (Figure B.1), modelling specifications (Table B.1) and detailed material balance (Table B.2) can be found in the Supplementary Materials (Appendix B). The gasification model was validated against the experimental study conducted by He et al. [30]. The model validation can be found in Table B.3 in the Supplementary Materials (Appendix B).

The rejected materials contain $26.8 \mathrm{wt} \%$ of moisture (Table 2). The flow of rejected materials (stream 19) at $2.55 \mathrm{t} / \mathrm{h}$ (wet basis; 8000 operating hours was assumed) or $1.9 \mathrm{t} / \mathrm{h}$ after drying at $110^{\circ} \mathrm{C}$ (dry basis; $10 \%$ moisture) is fed into a gasification process where partial oxidation takes place at $900^{\circ} \mathrm{C}$ and 1.6 bar in this case using steam (stream $20 ; 2.65 \mathrm{t} / \mathrm{h}$ ) as the gasifying medium [30]. The steam-to-feed ratio is assumed to be 1.04 on weight basis [30]. Syngas (stream 21: $4.1 \mathrm{t} / \mathrm{h}$ ) is generated from gasification consisting primarily of $\mathrm{CO}, \mathrm{H}_{2}, \mathrm{CO}_{2}$ and $\mathrm{H}_{2} \mathrm{O}$, with a $\mathrm{H}_{2} / \mathrm{CO}$ molar ratio of 2.6. The hot syngas is passed through a cyclone to remove ash (stream 22: $0.48 \mathrm{t} / \mathrm{h}$ ) which is then disposed of in landfill.

The syngas is cooled down to $80^{\circ} \mathrm{C}$ and compressed to 30 bar before entering the gas cleaning and conditioning processes. Tar is assumed to be negligible in this case where the steam-tofeed ratio of the gasification is high [30]. The gas cleaning and conditioning processes comprise acid gas removal units and a water-gas shift reactor. The acid gas removal units are needed to remove hydrogen sulphide $\left(\mathrm{H}_{2} \mathrm{~S}\right)$ in the syngas down to $1 \mathrm{ppmv}$ as a measure to prevent catalyst poisoning in the water-gas shift reactor. The water-gas shift reaction $\left(\mathrm{CO}+\mathrm{H}_{2} \mathrm{O} \rightarrow \mathrm{H}_{2}+\mathrm{CO}_{2}\right)$, operated at $200^{\circ} \mathrm{C}$, is served to increase the yield of $\mathrm{H}_{2}$. Medium-pressure (MP) steam (stream 23: $1.6 \mathrm{t} / \mathrm{h}$ ) at 14 bar and $250^{\circ} \mathrm{C}$ is added to facilitate the reaction. The flow rate of hydrogen is increased from $0.26 \mathrm{t} / \mathrm{h}$ (stream 21 ) to $0.36 \mathrm{t} / \mathrm{h}$ (stream 24) through the water-gas shift reaction. The amount of steam to be supplied to water-gas shift reactor was determined using sensitivity analysis presented in Table B.4 in the Supplementary Materials (Appendix B). The outlet stream from water-gas shift reaction is cooled down to $40^{\circ} \mathrm{C}$ so that water (stream $25: 1.77 \mathrm{t} / \mathrm{h}$ ) 
1 can be removed through a flash drum. It should be noted that stream 25 also contains $\mathrm{H}_{2} \mathrm{~S}$ of $20.012 \mathrm{t} / \mathrm{h}$ which is removed from the acid gas removal unit. The hydrogen-rich stream (stream $324: 3.9 \mathrm{t} / \mathrm{h}$ ) is then sent to a pressure swing adsorption (PSA) unit to recover hydrogen at 85 $4 \mathrm{~mol} \%$ and obtain a purity of $99.95 \mathrm{~mol} \%$ (stream 26: $0.3 \mathrm{t} / \mathrm{h}$ ), compressed to $70 \mathrm{bar}$. The tail 5 gas stream (stream 27: $3.6 \mathrm{t} / \mathrm{h}$ ) from PSA comprises mainly $\mathrm{CO}_{2}$.

6

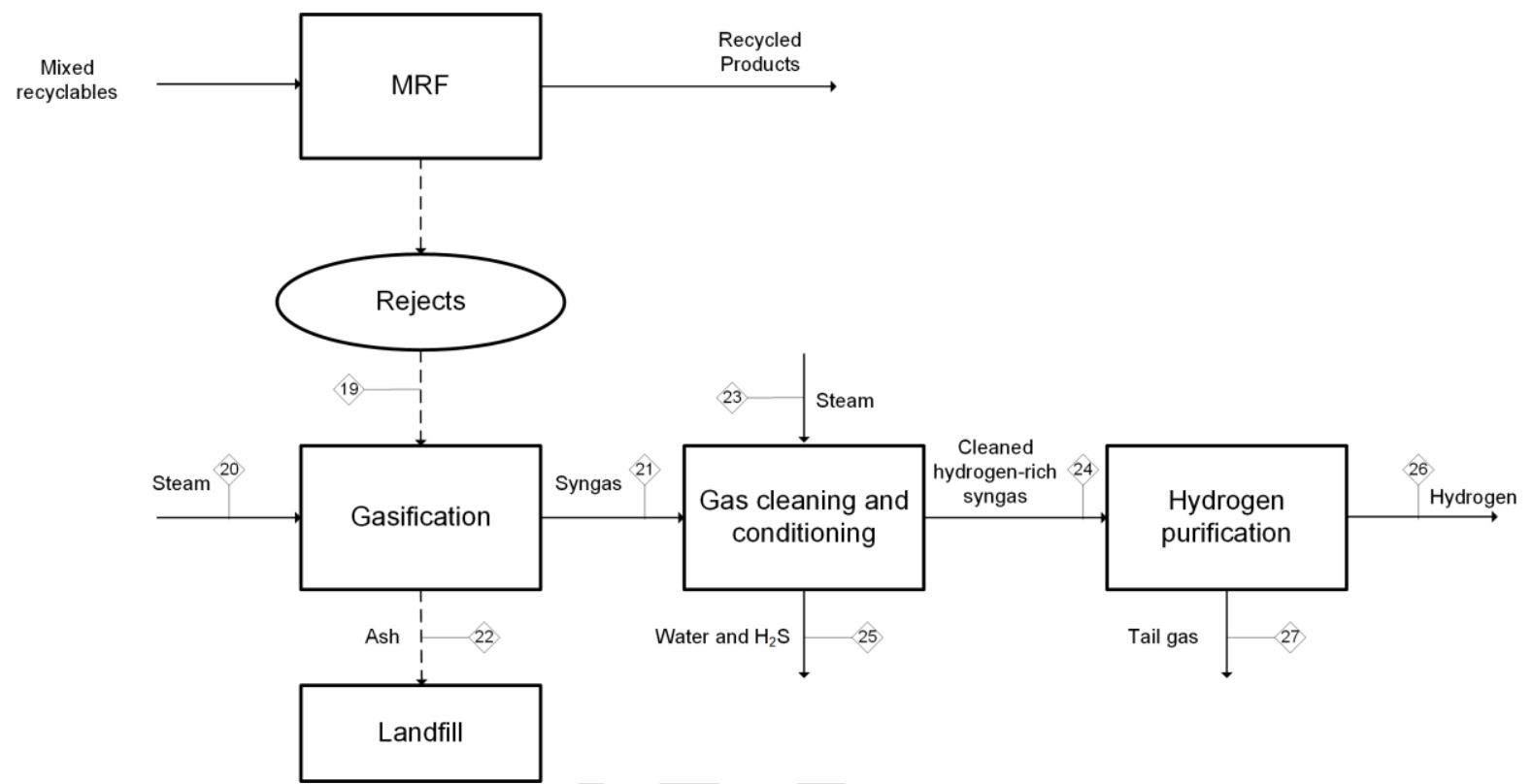

Figure 4: Integrated MRF and gasification system for material recovery and hydrogen production.

\subsubsection{Material and energy balances}

The material balance of the gasification system for converting MRF rejects into hydrogen is presented in Table 5. Detailed material balance estimated from Aspen Plus model can be found in Table B.2 in the Supplementary Materials (Appendix B). The material balance shows that $0.3 \mathrm{t} / \mathrm{h}(2502.5 \mathrm{t} / \mathrm{y})$ of hydrogen can be produced from gasification of rejects, resulting in a yield of $167.5 \mathrm{~kg}$ of hydrogen per dry tonne of rejects. 
1 Table 5: Material balance of Gasification- $\mathrm{H}_{2}$ system with 2 dry t/h MRF rejects input.

\begin{tabular}{|l|c|c|c|c|c|c|c|c|c|}
\hline \multirow{2}{*}{ Component } & \multicolumn{9}{|c|}{ Stream } \\
\cline { 2 - 10 } & $\mathbf{1 9}$ & $\mathbf{2 0}$ & $\mathbf{2 1}$ & $\mathbf{2 2}$ & $\mathbf{2 3}$ & $\mathbf{2 4}$ & $\mathbf{2 5}$ & $\mathbf{2 6}$ & $\mathbf{2 7}$ \\
\hline Mass flow (t/h) & & & & & & & & & \\
\hline $\mathrm{C}$ & 0.885 & 0.000 & 0.000 & 0.000 & 0.000 & 0.000 & 0.000 & 0.000 & 0.000 \\
\hline $\mathrm{H}_{2}$ & 0.114 & 0.000 & 0.264 & 0.000 & 0.000 & 0.364 & 0.000 & 0.310 & 0.055 \\
\hline $\mathrm{O}_{2}$ & 0.358 & 0.000 & 0.000 & 0.000 & 0.000 & 0.000 & 0.000 & 0.000 & 0.000 \\
\hline $\mathrm{N}_{2}$ & 0.020 & 0.000 & 0.020 & 0.000 & 0.000 & 0.020 & 0.000 & 0.000 & 0.020 \\
\hline $\mathrm{S}$ & 0.011 & 0.000 & 0.000 & 0.000 & 0.000 & 0.000 & 0.000 & 0.000 & 0.000 \\
\hline $\mathrm{CO}$ & 0.000 & 0.000 & 1.412 & 0.000 & 0.000 & 0.015 & 0.000 & 0.000 & 0.015 \\
\hline $\mathrm{CO}{ }_{2}$ & 0.000 & 0.000 & 1.023 & 0.000 & 0.000 & 3.219 & 0.000 & 0.003 & 3.216 \\
\hline $\mathrm{H}_{2} \mathrm{O}$ & 0.068 & 2.654 & 1.379 & 0.000 & 1.600 & 0.313 & 1.767 & 0.000 & 0.313 \\
\hline $\mathrm{CH}{ }_{4}$ & 0.000 & 0.000 & 0.001 & 0.000 & 0.000 & 0.001 & 0.000 & 0.000 & 0.001 \\
\hline $\mathrm{H}_{2} \mathrm{~S}$ & 0.000 & 0.000 & 0.012 & 0.000 & 0.000 & 0.000 & 0.012 & 0.000 & 0.000 \\
\hline Ash & 0.480 & 0.000 & 0.000 & 0.480 & 0.000 & 0.000 & 0.000 & 0.000 & 0.000 \\
\hline $\begin{array}{l}\text { Total mass flow } \\
(\mathbf{t} / \mathbf{h})\end{array}$ & $\mathbf{1 . 9 3 6}$ & $\mathbf{2 . 6 5 4}$ & $\mathbf{4 . 1 1 0}$ & $\mathbf{0 . 4 8 0}$ & $\mathbf{1 . 6 0 0}$ & $\mathbf{3 . 9 3 1}$ & $\mathbf{1 . 7 7 9}$ & $\mathbf{0 . 3 1 3}$ & $\mathbf{3 . 6 1 8}$ \\
\hline Temperature $\left({ }^{\circ} \mathrm{C}\right)$ & 250.0 & 133.5 & 900.0 & 900.0 & 250.0 & 40.0 & $50.0 / 40.0$ & 45.0 & 40.0 \\
\hline Pressure (bar) & 1.6 & 3.0 & 1.6 & 1.6 & 14.0 & 1.0 & $30.0 / 1.0$ & 70.0 & 1.0 \\
\hline
\end{tabular}

Note:

3 1. Stream 19 has been dried - assumed $10 \%$ moisture content left in the feedstock entering gasification.

4 2. Stream $25-2$ processes are involved in different stages, hence the temperature and pressure are different.

6 A comprehensive energy integration was performed on the Gasification- $\mathrm{H}_{2}$ system by adopting 7 the methodology discussed in section 2.3.2. Stream data were extracted from the flowsheet and 8 classification was carried out to identify the optimum strategies for heat utilisation as presented 9 in Table C.1 in the Supplementary Materials (Appendix C). A CHP network was designed as 10 illustrated in Figure C.1 in the Supplementary Materials (Appendix C), showing the steam 11 generation and distribution as well as power generation. The system is able to generate 12 sufficient steam to satisfy the requirement within the Gasification- $\mathrm{H}_{2}$ system. The CHP 13 network generates $1787 \mathrm{~kW}$ of power from steam turbines, which satisfies $54 \%$ of the total 14 electricity requirement of the Gasification $-\mathrm{H}_{2}$ system $(3305 \mathrm{~kW})$. Therefore, a net power requirement of $1518 \mathrm{~kW}$ is required, which is equivalent to $12143 \mathrm{MWh}$ per year of electricity requirement. The power balance is summarised in Table C.2 in the Supplementary Materials

17 (Appendix C). 


\section{Economic assessment}

2 Detailed economic assessment and scenario analysis of the conventional MRF and integrated 3 MRF and Gasification- $\mathrm{H}_{2}$ system are presented in sections 4.1 and 4.2, respectively. The key

4 findings are discussed in section 4.3.

5

6

7

4.1 Economic assessment of conventional MRF and integrated MRF and Gasification-

\section{$\mathrm{H}_{2}$ systems}

The EPs (Equation (5)) of conventional MRF and integrated MRF and Gasification- $\mathrm{H}_{2}$ systems were evaluated in terms of capital and operating costs and revenues as presented in Table 6.

Detailed cost evaluation can be found in the Supplementary Materials: Appendix A for MRF

(Tables A.4 - A.16) and Appendix B for Gasification- $\mathrm{H}_{2}$ (Tables B.5 - B.9) systems.

1 The conventional MRF gives an EP of 4 million $£ / y$ and it is highly dependent on the income 2 from gate fees which contributes $42 \%$ of the revenues. This poses significant threat to the 3 financial stability of the facility if lower gate fees are paid to the facility. The values of recycled 4 products are determined by the recycling market and they are highly unstable. The proposed 5 integrated system offers the advantage of generating a revenue stream of 25 million $£ / y$ 6 attributed to hydrogen production (assuming hydrogen price of $10 £ / \mathrm{kg}$ [44]), thus resulting in 7 an EP of 15.9 million $£ / y$. This provides greater financial stability to the facility considering 8 that the facility can be sustained even without receiving income from the gate fees. The analysis 9 in Table 6 suggests that an additional annual cost (capital and operating costs) of 15.2 million $20 £ / y$ is required if a Gasification- $\mathrm{H}_{2}$ system is to be incorporated. Nevertheless, the integrated 21 MRF and Gasification- $\mathrm{H}_{2}$ system obviates a reject/solid disposal cost of 1.6 million $£ / y$. 
Table 6: Economic assessment of conventional MRF and integrated MRF and Gasification- $\mathrm{H}_{2}$ systems.

\begin{tabular}{|c|c|c|c|c|c|}
\hline \multicolumn{2}{|c|}{ MRF } & \multicolumn{2}{|c|}{ Gasification-H2 } & \multicolumn{2}{|c|}{ Integrated MRF and Gasification- $\mathrm{H}_{2}$} \\
\hline Component & $\begin{array}{c}\text { Cost } \\
(\text { million } £ / y)\end{array}$ & Component & $\begin{array}{c}\text { Cost } \\
(\text { million } £ / y) \\
\end{array}$ & Component & $\begin{array}{c}\text { Cost } \\
(\text { million } \mathfrak{f} / \mathbf{y})\end{array}$ \\
\hline Capital cost & & Capital cost & & Capital cost & \\
\hline Equipment & 0.100 & Equipment & 1.73 & Equipment & 1.83 \\
\hline Conveyor & 0.003 & Dryer & 0.12 & MRF equipment & 0.10 \\
\hline Drum feeder & 0.009 & Gasifier & 0.19 & \begin{tabular}{|l|} 
Dryer \\
\end{tabular} & 0.12 \\
\hline Vacuum & 0.002 & Cyclone & 0.08 & Gasifier & 0.19 \\
\hline Trommel & 0.005 & Acid gas removal & 0.003 & Cyclone & 0.08 \\
\hline Ballistic separator & 0.011 & Water-gas shift reactor & 0.10 & Acid gas removal & 0.003 \\
\hline Magnet & 0.006 & Water removal unit & 0.003 & Water-gas shift reactor & 0.10 \\
\hline Eddy current separator & 0.008 & PSA & 0.28 & Water removal unit & 0.003 \\
\hline Air classifier & 0.002 & Syngas compressor & 0.39 & PSA & 0.28 \\
\hline Optical/NIR sorter & 0.027 & $\mathrm{H}_{2}$ compressor & 0.04 & Syngas compressor & 0.39 \\
\hline \multirow[t]{4}{*}{ Baler } & 0.029 & Heat exchangers & 0.35 & $\mathrm{H}_{2}$ compressor & 0.04 \\
\hline & & Steam turbine + steam system & 0.18 & Heat exchangers & 0.35 \\
\hline & & & & Steam turbine + steam system & 0.18 \\
\hline & & 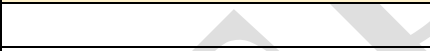 & 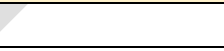 & & \\
\hline Other direct cost & 0.17 & Other direct cost & 4.49 & \begin{tabular}{|l|} 
Other direct cost \\
\end{tabular} & 4.66 \\
\hline Indirect cost & 0.13 & Indirect cost & 2.49 & Indirect cost & 2.62 \\
\hline Working capital & 0.07 & \begin{tabular}{|l|} 
Working capital \\
\end{tabular} & 1.54 & \begin{tabular}{|l|} 
Working capital \\
\end{tabular} & 1.61 \\
\hline Annualised capital cost & 0.47 & Annualised capital cost & 10.25 & Annualised capital cost & 10.71 \\
\hline & 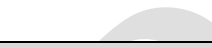 & 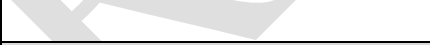 & & & \\
\hline Operating cost & & Operating cost & & Operating cost & \\
\hline Variable operating cost & 3.23 & Variable operating cost & 2.07 & \begin{tabular}{|l|} 
Variable operating cost \\
\end{tabular} & 3.23 \\
\hline Baling - wire cost & 0.14 & Electricity & 1.57 & Baling - wire cost & 0.14 \\
\hline Electricity & 0.05 & Catalyst & 0.006 & Fuel & 0.97 \\
\hline Fuel & 0.97 & LO-CAT chemicals & 0.004 & Electricity & 1.62 \\
\hline Rejects disposal cost & 2.07 & Gasifier bed materials & 0.04 & Catalyst & 0.006 \\
\hline & & Solid disposal cost & 0.44 & LO-CAT chemicals & 0.004 \\
\hline
\end{tabular}




\begin{tabular}{|c|c|c|c|c|c|}
\hline & & Effluent discharge cost & 0.01 & Gasifier bed materials & 0.04 \\
\hline & & & & \begin{tabular}{|l|} 
Solid disposal cost \\
\end{tabular} & 0.44 \\
\hline & & & & Effluent discharge cost & 0.01 \\
\hline Fixed operating cost & 0.55 & Fixed operating cost & 2.93 & \begin{tabular}{|l} 
Fixed operating cost \\
\end{tabular} & 3.49 \\
\hline & & & & 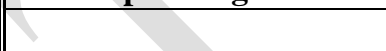 & \\
\hline Operating cost & 3.78 & Operating cost & 5.00 & Operating cost & 6.71 \\
\hline & & & & +2 & \\
\hline Revenue & & Revenue & & Revenue & \\
\hline Recycled products & -4.83 & Hydrogen & -25.03 & Recycled products & -4.83 \\
\hline Card and paper & -1.48 & & & Hydrogen & -25.03 \\
\hline Ferrous metals & -0.45 & & +2 & Gate fees for MRF & -3.50 \\
\hline Aluminium & -1.66 & & 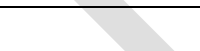 & 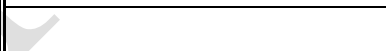 & \\
\hline Glass & 0.20 & & & & \\
\hline PET & -0.70 & & & & \\
\hline HDPE & -0.67 & & & & \\
\hline Mixed rigid plastics & -0.08 & & 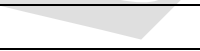 & & \\
\hline Gate fees for MRF & -3.50 & & & & \\
\hline Wate tes ioi inis & 5.50 & 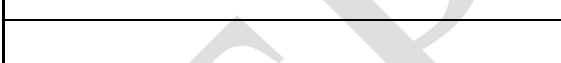 & 7 & & \\
\hline Revenue & -8.33 & Revenue & -25.03 & Revenue & -33.36 \\
\hline & & 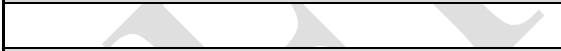 & & & \\
\hline Economic potential (EP) & 4.08 & Economic potential (EP) & 9.78 & Economic potential (EP) & 15.93 \\
\hline
\end{tabular}


1 A comparison of costs and revenues of conventional MRF and integrated systems is presented 2 in Figure 5. It is apparent that the capital cost is the major hurdle for introducing an integrated 3 MRF and Gasification- $\mathrm{H}_{2}$ system as it requires almost 23-fold of capital investment compared 4 to a standalone MRF. The operating cost of a Gasification- $\mathrm{H}_{2}$ system is around $32 \%$ higher than an MRF, hence the cost is doubled for the integrated system. Although higher capital and operating costs are incurred in the integrated system, the revenue generated is attractive where it could potentially bring 4 times more revenue compared to a conventional MRF. It should be noted that gate fees of 3.5 million $£ / y$ are paid by the local authorities to MRF, whereas there are currently no incentives given for advanced thermal systems such as gasification in the UK.

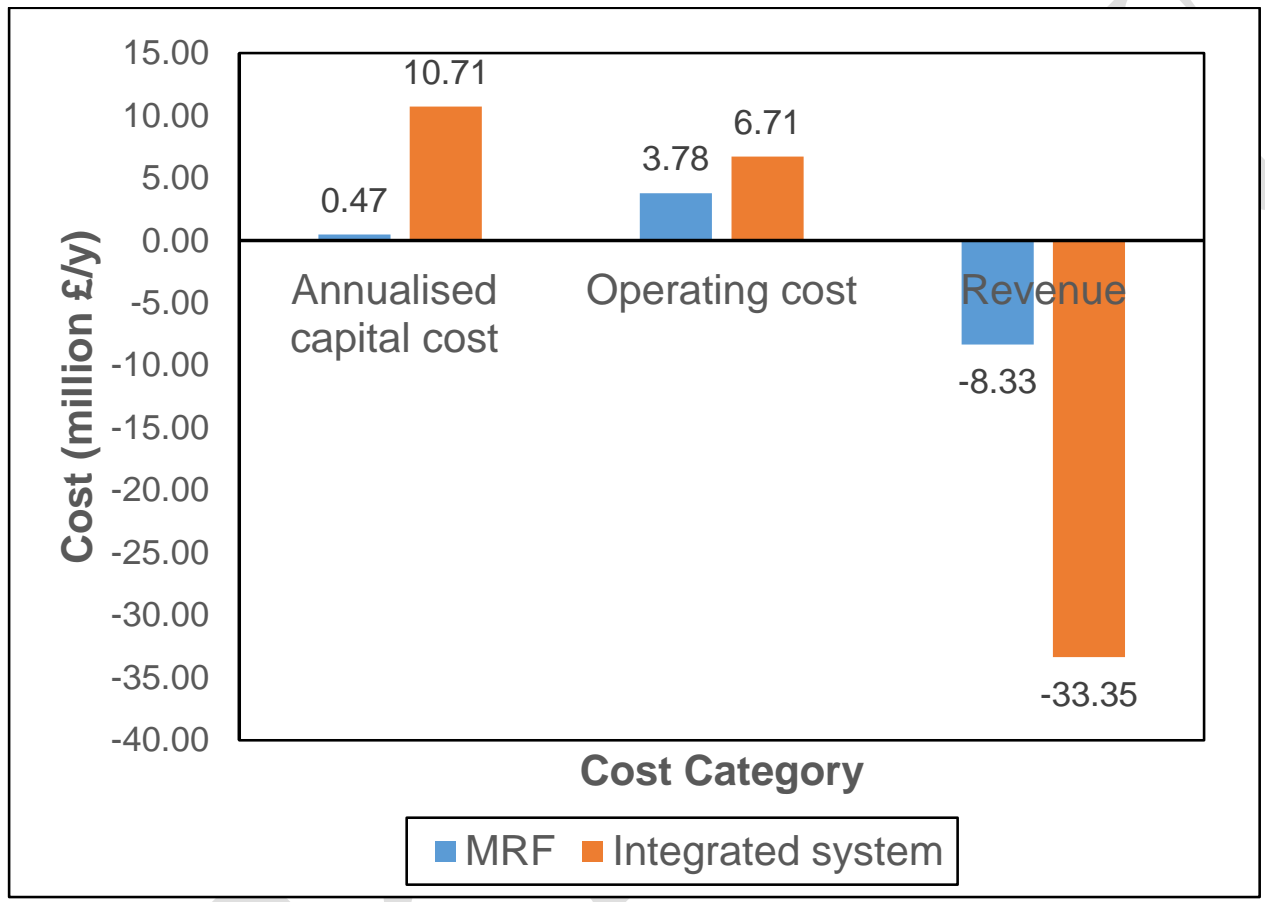

11 Figure 5: Comparison of annualised capital cost, operating cost and revenue of MRF and integrated systems.

12 Figure 6 provides insights into the capital cost of MRF (Figure 6(a)) and Gasification- $\mathrm{H}_{2}$ system (Figure 6(b)) by examining the cost contribution of individual piece of equipment. The equipment cost of MRF is dominated by baler (28.4\%), followed by optical/NIR sorter $(26.8 \%)$ and ballistic separator (11.3\%). On the other hand, the major equipment costs in the Gasification $-\mathrm{H}_{2}$ system are contributed by syngas compressor $(22.8 \%)$, followed by heat exchangers (20.1\%) and PSA unit (16.2\%).

The variable operating cost of the Gasification- $\mathrm{H}_{2}$ system ( 2.07 million $£ / y$ ) is lower than that of MRF (3.23 million £/y) in this study as illustrated in Figure 7. For MRF (Figure 7(a)), the reject disposal cost $(64.1 \%)$ is the largest contributor of the variable operating costs, followed by fuel $(30 \%)$. On the other hand, electricity $(75.7 \%)$ dominates the variable operating cost of 
1 Gasification- $\mathrm{H}_{2}$ system (Figure 7(b)), followed by solid disposal cost (21.2\%). Hence, there is 2 a strong motivation to minimise the cost of reject/solid disposal and impact on the environment 3 through recovering the resources embedded in the non-recyclable streams of MRF. The 4 electricity requirement in the Gasification- $\mathrm{H}_{2}$ system is primarily for syngas $(3117.4 \mathrm{~kW})$ and $5 \quad \mathrm{H}_{2}$ compressors $(187.2 \mathrm{~kW})$. In this study, it was demonstrated that energy integration through 6 CHP generation enables $54 \%$ of electricity $(1787 \mathrm{~kW})$ in the Gasification- $\mathrm{H}_{2}$ system to be 7 recovered on-site (Supplementary Materials: Appendix C). This portion of energy recovered is 8 equivalent to 1.8 million $f / y$ of cost saving on electricity, however at the expense of 0.18 9 million $£ / y$ on steam turbine and steam system.

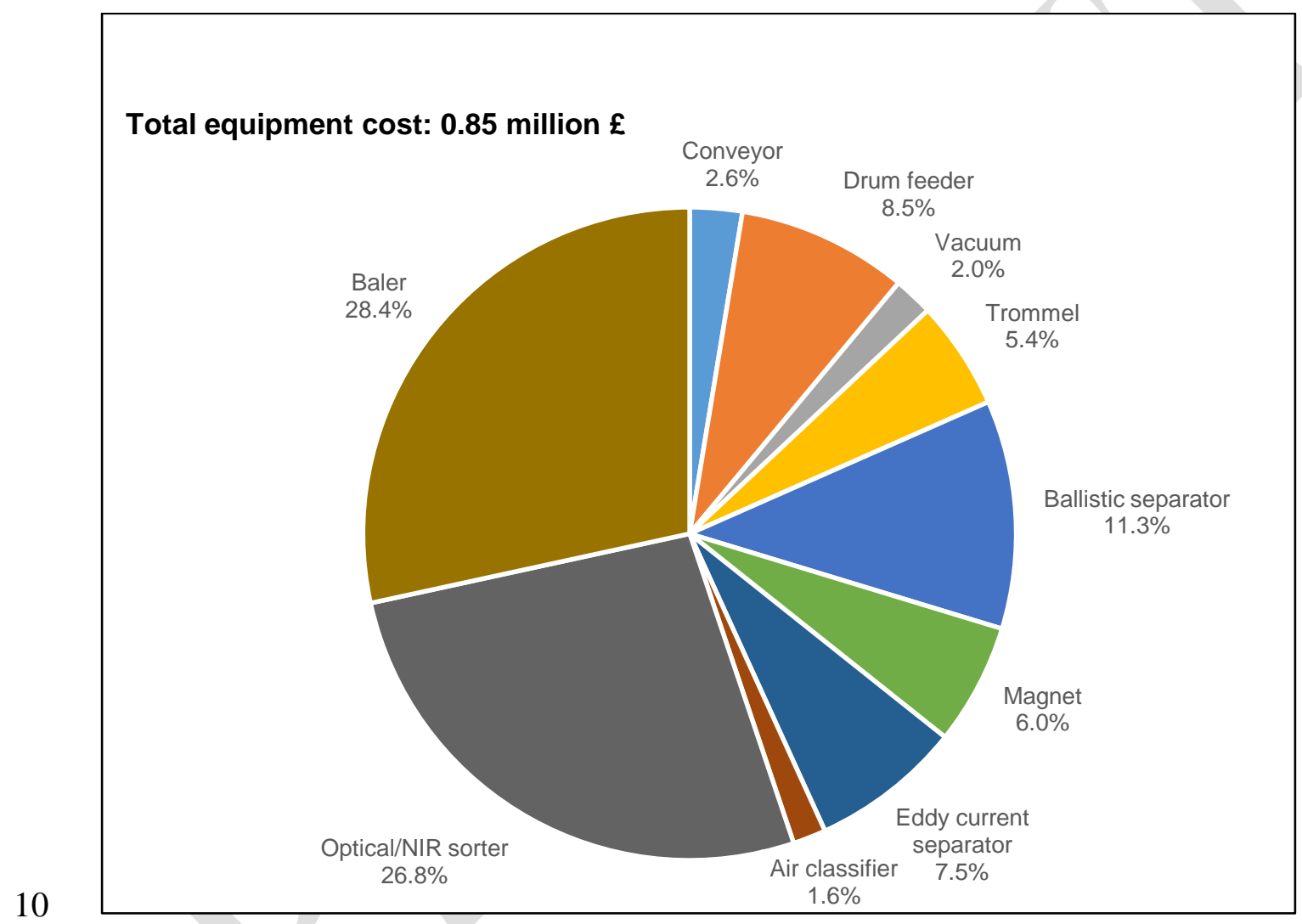




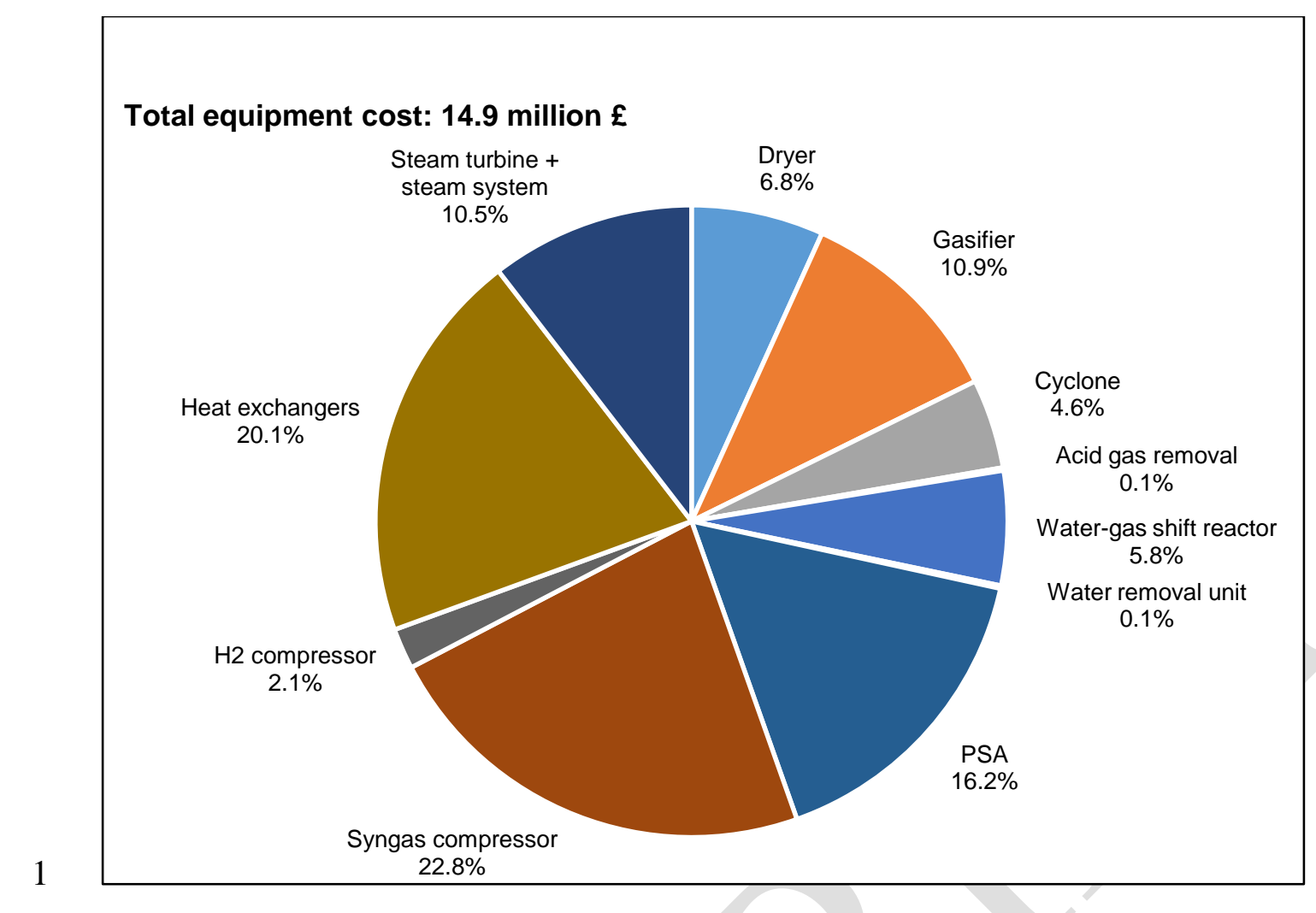

(b)

3 Figure 6: Equipment cost breakdown (a) MRF; (b) Gasification- $\mathrm{H}_{2}$.

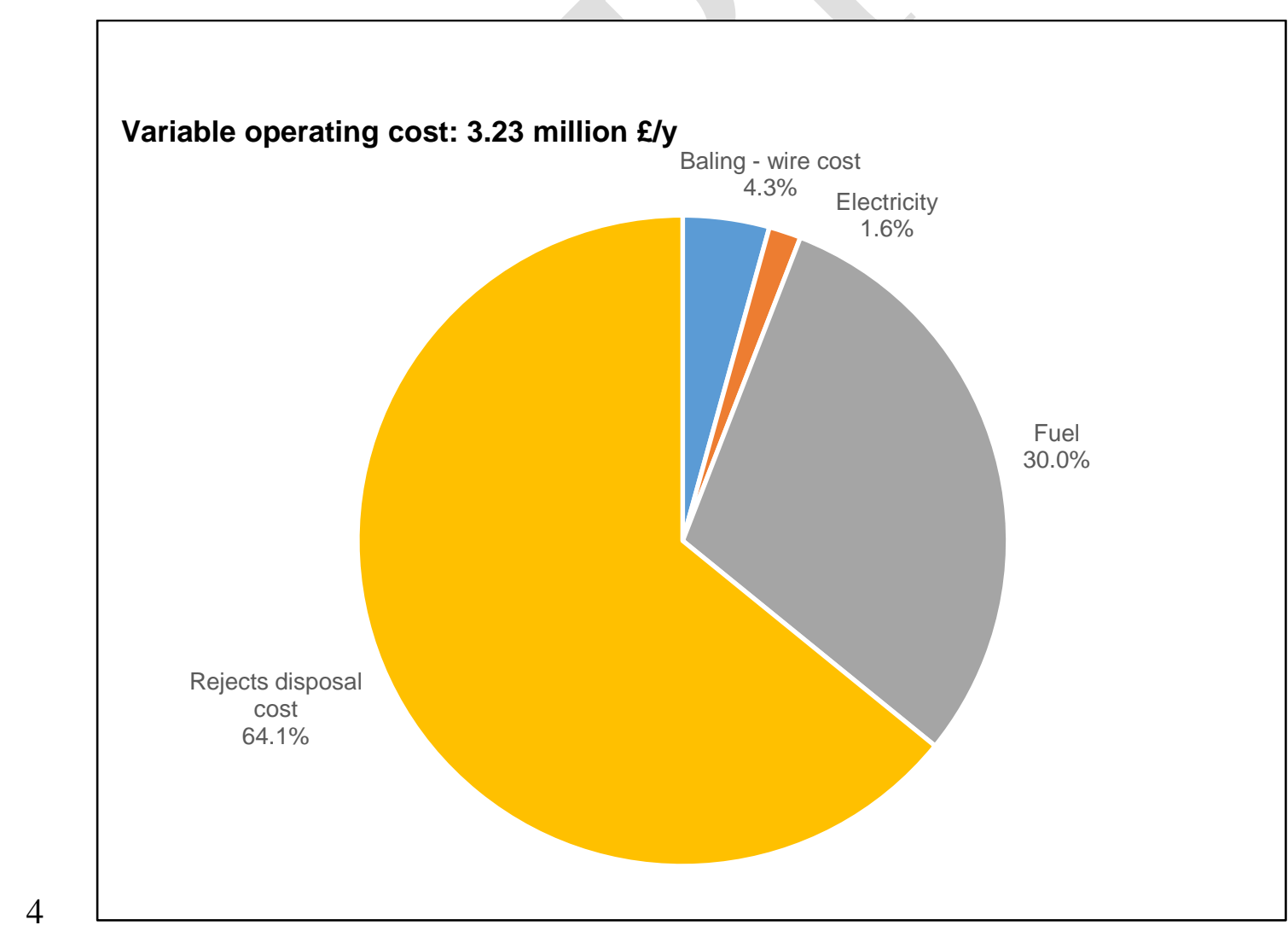

(a) 


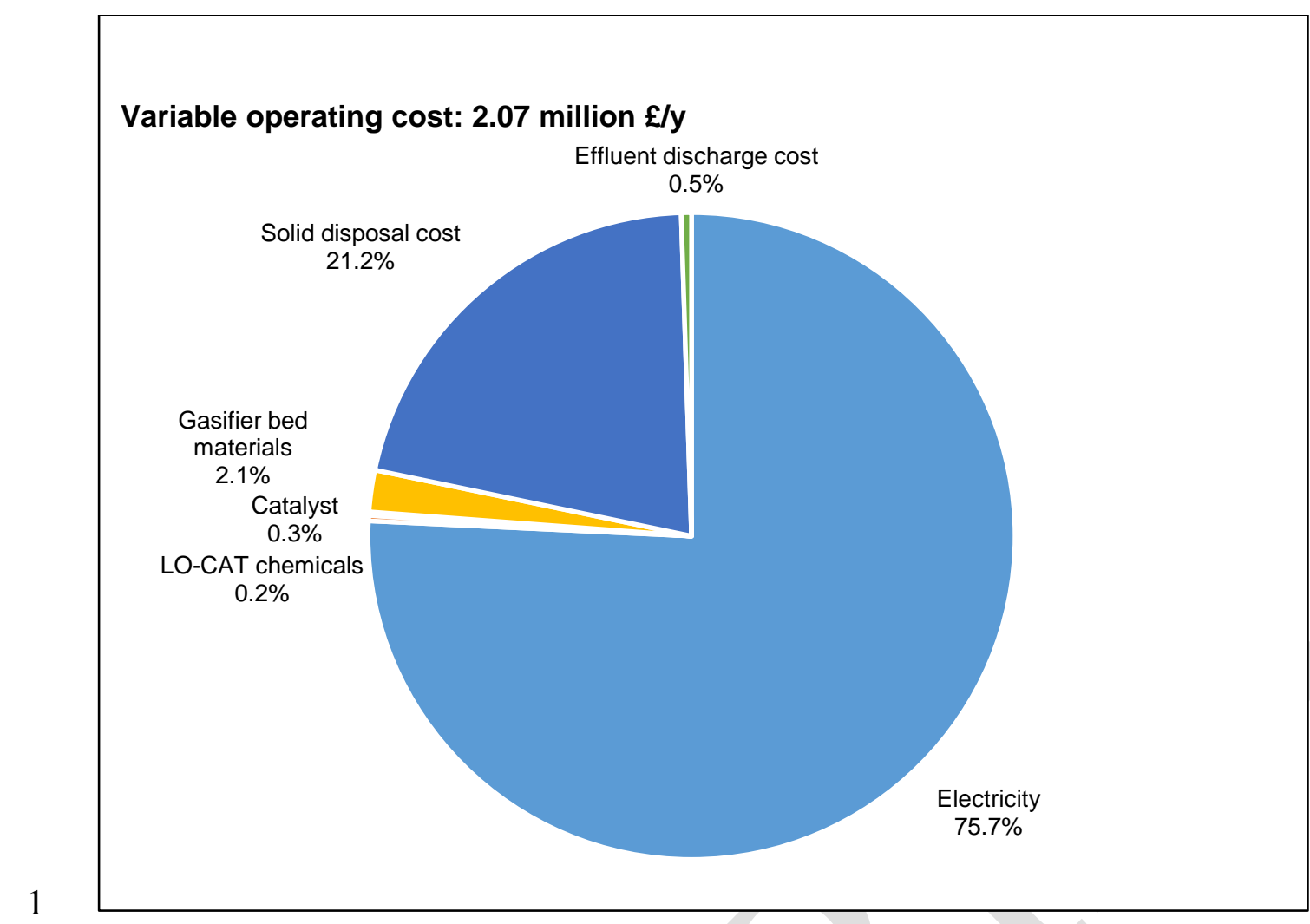

3 Figure 7: Variable operating cost breakdown (a) MRF; (b) Gasification- $\mathrm{H}_{2}$.

\subsection{Scenario analysis}

5 Economic assessment of the MRF scenario with enhanced separation efficiency (Scenario 1) and the Gasification- $\mathrm{H}_{2}$ system with increased throughput (Scenario 2) are presented in sections 4.2.1 and 4.2.2, respectively.

\subsubsection{Scenario 1: Enhancing separation efficiency of MRF}

9 In this scenario, it was assumed that the separation efficiencies of sorting/screening equipment in MRF (Supplementary Materials: Appendix A, Table A.2) were increased from $83-91 \%$ to $98 \%$. It was found that the amount of rejects was reduced by $37.3 \%$ (from 3.78 to $2.37 \mathrm{t} / \mathrm{h}$ ).

12 This implies that $12.8 \%$ of rejected materials (relative to the mixed recyclables input) were 13 generated compared to the base case of $20.4 \%$. In this scenario, more materials were recovered 14 and sold, resulting in a $6 \%$ increase in revenue (i.e. 0.5 million $£ / y$ ). Furthermore, an $18 \%$ 15 reduction in operating cost was attained and this was mainly attributed to an obviated rejects 16 disposal cost of approximately 0.7 million $£ / y$. The EP was improved by 1.3 million $£ / y$ (30\%) 17 in this scenario where enhanced separation efficiency of MRF was considered, presented in 18 Table 7. 
2 Table 7: Economic analysis of Scenario 1 with enhancement of MRF separation efficiency.

\begin{tabular}{|l|c|c|c|}
\hline \multicolumn{1}{|c|}{ Parameter } & Unit & $\begin{array}{c}\text { Base } \\
\text { case }\end{array}$ & $\begin{array}{c}\text { Scenario 1: } \\
\text { Enhanced } \\
\text { separation } \\
\text { efficiency }\end{array}$ \\
\hline Throughput (Mixed recyclables) & t/h & 18.52 & 18.52 \\
\hline Total rejects & t/h & 3.78 & 2.37 \\
\hline Percentage of rejects with respect to mixed recyclables input & $\%$ & 20.42 & 12.77 \\
\hline & & & \\
\hline Annualised capital cost & million $£ / y$ & 0.47 & 0.44 \\
\hline Operating cost & million $£ / y$ & 3.78 & 3.07 \\
\hline Revenue & million $£ / y$ & 8.33 & 8.85 \\
\hline Economic potential (EP) & million $£ / y$ & $\mathbf{4 . 0 8}$ & $\mathbf{5 . 3 4}$ \\
\hline
\end{tabular}

\subsubsection{Scenario 2: Increasing throughput to Gasification-H2 $\mathrm{H}_{2}$ system}

5 This scenario examines the economies of scale of the Gasification- $\mathrm{H}_{2}$ system if the throughput

6 of rejected materials from MRF is increased from 1.87 to 100 dry $\mathrm{t} / \mathrm{h}$. As indicated in Table 8 ,

7 by keeping similar hydrogen yield of approximately $160 \mathrm{~kg} / \mathrm{dry} \mathrm{t}$ feedstock, the annualised

8 capital and operating costs, revenues and EP were increased as expected. The MHSP was

9 reduced considerably from $6.1 £ / \mathrm{kg}$ (base case) to $2.2 £ / \mathrm{kg}$. This suggests that economies of

10 scale play a vital role in reducing the MHSP, i.e. improving the economic performance of the

11 system.

12 Table 8: Economic analysis of Scenario 2 with increase of MRF rejected materials throughput into Gasification-

$13 \mathrm{H}_{2}$ system.

\begin{tabular}{|c|c|c|c|}
\hline Parameter & Unit & Base case & $\begin{array}{l}\text { Scenario 2: High } \\
\text { throughput }\end{array}$ \\
\hline Throughput (Rejected materials from MRF) & dry $\mathrm{t} / \mathrm{h}$ & 1.87 & 100.00 \\
\hline & & & \\
\hline Annualised capital cost & million $£ / y$ & 10.24 & 169.90 \\
\hline Operating cost & million $£ / y$ & 5.00 & 126.56 \\
\hline Revenue & million $£ / y$ & 25.03 & 1328.78 \\
\hline Economic potential (EP) & million $\mathfrak{£} / \mathbf{y}$ & 9.78 & 1032.32 \\
\hline 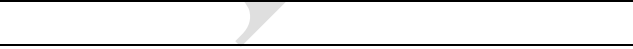 & & & \\
\hline Hydrogen production & $\mathrm{t} / \mathrm{y}$ & 2502.52 & 132877.60 \\
\hline Hydrogen yield & $\mathrm{kg} /$ dry $\mathrm{t}$ feedstock & 167.49 & 166.10 \\
\hline Minimum hydrogen selling price (MHSP) & $\mathfrak{f} / \mathbf{k g}$ & 6.09 & 2.23 \\
\hline Minimum hydrogen selling price (MHSP) & £/GJ & $\mathbf{5 0 . 7 7}$ & 18.59 \\
\hline
\end{tabular}




\subsection{Discussions}

2 Plant design and incoming waste composition have strong influence on the MRF performance,

3 as pointed out by Pressley et al. [21]. Changes in MRF and gasification configurations and

4 operating conditions may have an impact on the performance of the system. Hence, technoeconomic evaluation needs to be conducted on a case-by-case basis. One of the limitations of this work is the assumptions made for incoming waste composition and rejected materials composition and properties since actual plant data are not available. The UK data for waste composition have not indicated the ratio of recyclable and non-recyclable fractions for each waste category in the mixed recyclable stream, as discussed in section 3.1. An assumption for this ratio was made based on the work of Pressley et al. [21]. This assumption however is sensible for a pre-sorted stream where non-recyclable fraction is typically kept to a minimum. This fraction is not expected to vary significantly unless there is an apparent deficiency in the source-segregation and collection stages. The variability of waste composition (i.e. chemical properties, recyclable/non-recyclable fraction, combustible/non-combustible fraction) has certain impact on the economic performance of the system and this aspect needs to be considered in the design stage. For an MRF plant, reducing $1 \%$ of the non-recyclable fraction (i.e. $1 \%$ higher in the recyclable fraction) would lead to an increase in revenue from 0.01 million $£ / y$ (aluminium; highest unit price) to 0.02 million $£ / y$ (cards/papers; lowest unit prices) for the recycled products. Higher non-recyclable fraction implies higher production of rejected materials and thus higher cost for solid disposal, i.e. $1 \%$ increase in rejected materials would incur an additional 0.02 million $£ / y$ for treatment in EfW and landfill. Introducing the Gasification $-\mathrm{H}_{2}$ system allows the rejected materials to be valorised into hydrogen, where $1 \%$ increase in rejected materials would create an additional revenue of 0.18 million $£ / y$.

MHSP estimated from the present study was compared against previous studies conducted by NREL [28] and Sara et al. [29] as summarised in Table 9. These studies have used biomass as feedstock for the Gasification- $\mathrm{H}_{2}$ system with different throughput. The current system with $1.87 \mathrm{dry} \mathrm{t} / \mathrm{h}$ of throughput gives a MHSP of $6.1 £ / \mathrm{kg}$, which falls within the range between 0.7 $£ / \mathrm{kg}$ at a higher throughput of $88.17 \mathrm{dry} \mathrm{t} / \mathrm{h}$ and $8.9 £ / \mathrm{kg}$ at a lower throughput of $0.02 \mathrm{dry} \mathrm{t} / \mathrm{h}$. Although the hydrogen yield predicted in the present study is the highest and more than double compared to those in other studies, i.e. 167 compared to $70 \mathrm{~kg}$ hydrogen/dry tonne of feedstock, the MHSP is still the highest among others. It should be noted that the $\mathrm{H}_{2} / \mathrm{CO}$ molar ratio of syngas from gasification in this study is 2.6 whereas the typical value is around 0.6-0.8 [28]. 
1 According to the results from Scenario 2 together with this comparison, it can be concluded 2 that economies of scale are critical factors in determining the economic viability of hydrogen 3 production from waste. A preliminary speculation suggests that a throughput of MRF rejected materials higher than 100 dry $t / h$ is essential to result in an MHSP competitive to the one estimated by NREL study [28]. In the present study, it was assumed that a single MRF is integrated with a Gasification- $\mathrm{H}_{2}$ system. Therefore, it would be more sensible to establish multiple MRF integrated with a larger scale Gasification- $\mathrm{H}_{2}$ system.

Table 9: Comparison of minimum hydrogen selling price (MHSP).

\begin{tabular}{|l|c|c|c|c|}
\hline \multicolumn{1}{|c|}{ Parameter } & Unit & Present study & NREL [28] & Sara et al. [29] \\
\hline Year of study & & 2020 & 2005 & 2016 \\
\hline Feedstock & & MRF rejects & $\begin{array}{c}\text { Hybrid poplar } \\
\text { wood chips }\end{array}$ & Almond shell \\
\hline Throughput & dry t/h & 1.87 & 88.17 & 0.02 \\
\hline Annualised capital cost & $\begin{array}{c}\text { million } \\
£ / y\end{array}$ & 10.24 & $14.23^{\text {(i) }}$ & $0.05^{\text {(ii) }}$ \\
\hline Operating cost & $\begin{array}{c}\text { million } \\
£ / y\end{array}$ & 5.00 & $23.40^{\text {(i) }}$ & $0.03^{\text {(ii) }}$ \\
\hline Hydrogen production & t/y & 2502.52 & 54400.00 & $9.70^{2}$ \\
\hline Hydrogen yield & $\begin{array}{c}\mathrm{kg} / \mathrm{dry} \mathrm{t} \\
\text { feedstock }\end{array}$ & 167.49 & $70.40^{2}$ & $69.29^{\text {(ii) }}$ \\
\hline Minimum hydrogen selling price (MHSP) & $£ / \mathrm{kg}$ & 6.09 & $0.69^{\text {(i) }}$ & $8.93^{\text {(i) }}$ \\
\hline Minimum hydrogen selling price (MHSP) & $£ / G J$ & 50.77 & $5.75^{\text {(i) }}$ & $74.38^{\text {(ii) }}$ \\
\hline
\end{tabular}

Note:

$10 \quad$ (i) Currency conversion of 1 USD $=0.5$ GBP was applied.

11 (ii) Currency conversion of $1 \mathrm{EURO}=0.7$ GBP was applied.

12

MHSP estimated from the present study was also compared against the MHSP of other hydrogen production technologies obtained from IRENA report [24], including solar PV and wind powered electrolysers, steam methane reforming (SMR) of natural gas with carbon capture and storage (CCS) and coal gasification with CCS as presented in

Table 10. The base case with lower throughput of MRF rejected materials ( 2 dry $t / h$ ) has the highest MHSP among all cases, however a higher throughput (100 dry $\mathrm{t} / \mathrm{h}$ ) has the potential of reducing the MHSP to $2.23 \mathrm{f} / \mathrm{kg}$ which is competitive with "green" hydrogen generated from an average-cost solar PV powered electrolyser (i.e. $2.27 £ / \mathrm{kg}$ ). Nevertheless, the MHSP for the waste-to-hydrogen system in the present study is difficult to compete with the conventional fossil-based SMR of natural gas $(0.27-0.73 £ / \mathrm{kg})$ and coal gasification $(0.14-0.36 £ / \mathrm{kg})$. As gathered from Scenario 2, the MHSP of the Gasification- $\mathrm{H}_{2}$ case can be further reduced if hydrogen is produced from a large-scale system, i.e. greater than 100 dry t/h of rejected materials. 
2 Table 10: Comparison of MHSP of various hydrogen production technologies.

\begin{tabular}{|l|c|c|}
\hline \multicolumn{1}{|c|}{ Hydrogen production technology } & £/GJ & £/kg \\
\hline Base case - Reject gasification- $\mathrm{H}_{2}$ (low throughput) & 50.77 & 6.09 \\
\hline Scenario 2 - Reject gasification- $\mathrm{H}_{2}$ (high throughput) & 18.59 & 2.23 \\
\hline Average-cost solar PV powered electrolyser & 18.89 & 2.27 \\
\hline Average-cost wind powered electrolyser & 7.78 & 0.93 \\
\hline Low-cost solar PV powered electrolyser & 3.89 & 0.47 \\
\hline Low-cost wind powered electrolyser & 5.11 & 0.61 \\
\hline SMR natural gas with CCS (low cost case) & 2.27 & 0.27 \\
\hline SMR natural gas with CCS (high cost case) & 6.07 & 0.73 \\
\hline Coal gasification with CCS (low cost case) & 1.20 & 0.14 \\
\hline Coal gasification with CCS (high cost case) & 3.04 & 0.36 \\
\hline
\end{tabular}

3

4 The conceptual model and techno-economic results in this study provide comprehensive

5 comparison between new and existing technologies using best available published data. The

6 MRF and gasification models developed in this study provide useful information and can be

7 adapted for future research to investigate different valorisation pathways. The economic

8 assessment has also identified areas in the integrated system which can be further improved. A

9 more rigorous model validation with detailed waste feedstock characterisation is needed if the

10 integrated system concept is to be implemented at pilot or commercial scale in the future.

\section{Conclusions}

13 A more robust resource recovery from waste concept through integrating material recovery and valorisation system is developed. This paper has established a conceptual design and modelling framework for an integrated material recovery and waste-to-hydrogen system through combining MRF and Gasification- $\mathrm{H}_{2}$ system. The analysis consists of flowsheet synthesis, material and energy balances, energy integration, economic assessment and scenario analysis. In this study, it is shown that reject/solid disposal not only poses significant impacts on the economics of MRF but also causes environmental pollution. One of the main advantages of this integrated system is that the high reject disposal cost in MRF can be obviated by transforming low-value rejected materials into hydrogen which is a high value-added products. This has significantly maximised the overall resource utilisation from household mixed recyclable stream, which is more promising than the conventional approach of using rejected materials in EfW or landfilling. Scenario analysis has demonstrated that the economic potential can be further enhanced by increasing separation efficiency of MRF. For the Gasification- $\mathrm{H}_{2}$ 
1 system, economies of scale are the predominant factors in determining an economically viable 2 production of hydrogen from waste. A large-scale system is desirable to achieve a costcompetitive production of hydrogen. It is recommended that an economically compelling waste-to-hydrogen system should comprise multiple MRF integrated with a large-scale Gasification $-\mathrm{H}_{2}$ system, i.e. greater than 100 dry $\mathrm{t} / \mathrm{h}$ of $\mathrm{MRF}$ rejects input. A more rigorous model validation for mass and energy balances through experimental and pilot plant studies is recommended. This should also incorporate the investigation on the variability of waste composition and associated impact on hydrogen production potential and economic performance of the integrated system.

\section{Acknowledgement}

11 This work was supported by the Natural Environment Research Council (NE/R012938/1) 12 through the UKRI/NERC Industrial Innovation Fellowship Programme.

\section{References}

14 [1] WRAP. 2014. Recovering value from MRFs.

15 https://www.wrap.org.uk/sites/files/wrap/RecoveringValueMRFs.3644.pdf (accessed 19 May 16 2020).

17 [2] Ali, M., Courtenay, P., 2014. Evaluating the progress of the UK's Material Recycling 18 Facilities: A mini review. Waste Management \& Research. 32(12): 1149-1157.

19 [3] WRAP. 2015. Dry recyclables: Improving quality, cutting contamination.

20 https://www.wrap.org.uk/sites/files/wrap/Dry\%20Recyclables\%20Improving\%20Quality\%20

21 Cutting\%20Contamination.pdf (accessed 25 April 2020).

22 [4] Damgacioglu, H., Hornilla, M., Bafail, O., Celik, N., 2020. Recovering value from 23 single stream material recovery facilities - An outbound contamination analysis in Florida. 24 Waste Management. 102: 804-814.

25 [5] Lakhan, C., 2015. A comparison of single and multi-stream recycling systems in 26 Ontario, Canada. Resources. 4: 384-397.

27 [6] Department for Environment, Food and Rural Affairs (DEFRA). 2014. Energy from 28 waste: A guide to the debate.

29 https://assets.publishing.service.gov.uk/government/uploads/system/uploads/attachment_data

30 /file/284612/pb14130-energy-waste-201402.pdf (accessed 19 May 2020). 
1 [7] AMEC Environment \& Infrastructure UK Limited. 2013. The Chartered Institution of

2 Wastes Management (CIWM) research into SRF and RDF exports to other EU countries.

3 https://www.ciwm.co.uk/Custom/BSIDocumentSelector/Pages/DocumentViewer.aspx?id=Q

4 oR7FzWBtisamYEcWSfL6SxAJRLAPT9vf9UOxY7TX\%252bRTmuWeo5keV9skGIWyOY

$5 \quad$ \%252bUp7ncAXRDbF5GQWy\%252bL3ZD1svIqkmjQD8b\%252bRybjUOcZx\%252bbtUeO

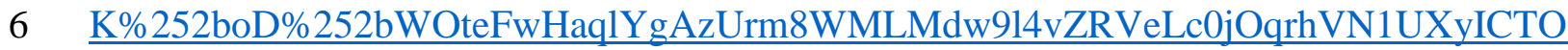

$7 \quad$ McvHDJhyoW\%252b1C2Q\%253d\%253d (accessed 20 May 2020).

8 [8] Násner, A.M.L., Lora, E.E.S., Palacio, J.C.E., Rocha, M.H., Restrepo, J.C., Venturini,

9 O.J., Ratner, A., 2017. Refuse derived fuel (RDF) production and gasification in a pilot plant

10 integrated with an Otto cycle ICE through Aspen plus ${ }^{\mathrm{TM}}$ modelling: Thermodynamic and

11 economic viability. Waste Management. 69: 187-201.

12 [9] Kabalina, N., Costa, M., Yang, W., Martin, A., 2017. Energy and economic

13 assessment of a polygeneration district heating and cooling system based on gasification of

14 refuse derived fuels. Energy. 137: 696-705.

15 [10] Hervy, M., Remy, D., Dufour, A., Mauviel, G., 2019. Air-blown gasification of Solid

16 Recovered Fuels (SRFs) in lab-scale bubbling fluidized-bed: Influence of the operating

17 conditions and of the SRF composition. Energy Conversion and Management. 181: 584-592.

18 [11] Nobre, C., Vilarinho, C., Alves, O., Mendes, B., Gonçalves, M., 2019. Upgrading of

19 refuse derived fuel through torrefaction and carbonization: Evaluation of RDF char fuel

20 properties. Energy. 181: 66-76.

21 [12] Białowiec, A., Pulka, J., Stępień, P., Manczarski, P., Gołaszewski, J., 2017. The

$22 \mathrm{RDF} / \mathrm{SRF}$ torrefaction: An effect of temperature on characterization of the product -

23 Carbonized Refuse Derived Fuel. Waste Management. 70: 91-100.

24 [13] Recari, J., Berrueco, C., Puy, N., Alier, S., Bartrolí, J., Farriol, X., 2017. Torrefaction 25 of a solid recovered fuel (SRF) to improve the fuel properties for gasification processes.

26 Applied Energy. 203: 177-188.

27 [14] Whyte, H.E., Loubar, K., Awad, S., Tazerout, M., 2015. Pyrolytic oil production by

28 catalytic pyrolysis of refuse-derived fuels: Investigation of low cost catalysts. Fuel Processing

29 Technology. 140: 32-38. 
1 [15] Sieradzka, M., Rajca, P., Zajemska, M., Mlonka-Mędrala, A., Magdziarz, A., 2020.

2 Prediction of gaseous products from refuse derived fuel pyrolysis using chemical modelling

3 software - Ansys Chemkin-Pro. Journal of Cleaner Production. 248: 119277.

4 [16] Consonni, S., Viganò, F., 2011. Material and energy recovery in integrated waste

5 management systems: The potential for energy recovery. Waste Management. 31(9): 2074-

62084.

7 [17] Chen, C.-C., Chen, Y.-T., 2013. Energy recovery or material recovery for MSW

8 treatments? Resources, Conservation and Recycling. 74: 37-44.

9 [18] Kendall, A., 2012. A life cycle assessment of biopolymer production from material 10 recovery facility residuals. Resources, Conservation and Recycling. 61: 69-74.

11 [19] Borgogna, A., Salladini, A., Spadacini, L., Pitrelli, A., Annesini, M.C., Iaquaniello, 12 G., 2019. Methanol production from refuse derived fuel: Influence of feedstock composition 13 on process yield through gasification analysis. Journal of Cleaner Production. 235: 1080141089.

15 [20] Cimpan, C., Maul, A., Wenzel, H., Pretz, T., 2016. Techno-economic assessment of 16 central sorting at material recovery facilities - the case of lightweight packaging waste.

17 Journal of Cleaner Production. 112: 4387-4397.

18 [21] Pressley, P.N., Levis, J.W., Damgaard, A., Barlaz, M.A., DeCarolis, J.F., 2015.

19 Analysis of material recovery facilities for use in life-cycle assessment. Waste Management. 20 35: $307-317$.

21 [22] International Energy Agency (IEA). 2019. The future of hydrogen: seizing today's opportunities. https://webstore.iea.org/the-future-of-hydrogen (accessed $20 \mathrm{Feb} 2020$ ).

23 [23] Gupta, R.B., 2009. Hydrogen Fuel: Production, Transport, and Storage. CRC Press, 24 Boca Raton, Florida.

[24] IRENA. 2019. Hydrogen: A Renewable energy perspective. https://irena.org/-

26 /media/Files/IRENA/Agency/Publication/2019/Sep/IRENA_Hydrogen_2019.pdf (accessed 2720 May 2020).

[25] Lui, J., Chen, W.-H., Tsang, D.C.W., You, S., 2020. A critical review on the 29 principles, applications, and challenges of waste-to-hydrogen technologies. Renewable and 30 Sustainable Energy Reviews. 134: 110365. 
1 [26] Shahabuddin, M., Krishna, B.B., Bhaskar, T., Perkins, G., 2020. Advances in the

2 thermo-chemical production of hydrogen from biomass and residual wastes: Summary of

3 recent techno-economic analyses. Bioresource Technology. 299: 122557.

4 [27] Chandrasekhar, K., Kumar, S., Lee, B.-D., Kim, S.-H., 2020. Waste based hydrogen

5 production for circular bioeconomy: Current status and future directions. Bioresource

6 Technology. 302: 122920.

7 [28] Spath, P., Aden, A., Eggeman, T., Ringer, M., Wallace, B., Jechura, J. NREL. 2005.

8 Biomass to hydrogen production detailed design and economics utilizing the Battelle

9 Columbus Laboratory indirectly heated gasifier. NREL/TP-510-37408.

10 http://neotericsint.com/pubs/BCL\%20Gasifier.pdf (accessed 3 May 2020).

11 [29] Sara, H.R., Enrico, B., Mauro, V., Andrea, D.C., Vincenzo, N., 2016. Techno-

12 economic analysis of hydrogen production using biomass gasification- a small scale power

13 plant study. Energy Procedia. 101: 806-813.

14 [30] He, M., Xiao, B., Liu, S., Guo, X., Luo, S., Xu, Z., Feng, Y., Hu, Z., 2009.

15 Hydrogen-rich gas from catalytic steam gasification of municipal solid waste (MSW):

16 Influence of steam to MSW ratios and weight hourly space velocity on gas production and

17 composition. International Journal of Hydrogen Energy. 34(5): 2174-2183.

18 [31] Rudra, S., Tesfagaber, Y.K., 2019. Future district heating plant integrated with 19 municipal solid waste (MSW) gasification for hydrogen production. Energy. 180: 881-892.

20 [32] Ng, K.S., Yang, A., Yakovleva, N., 2019. Sustainable waste management through

21 synergistic utilisation of commercial and domestic organic waste for efficient resource

22 recovery and valorisation in the UK. Journal of Cleaner Production. 227: 248-262.

23 [33] Ng, K.S., To, L.S., 2020. A systems thinking approach to stimulating and enhancing 24 resource efficiency and circularity in households. Journal of Cleaner Production. 275:

$25 \quad 123038$.

26 [34] Ng, K.S., Zhang, N., Sadhukhan, J., 2013. Techno-economic analysis of 27 polygeneration systems with carbon capture and storage and $\mathrm{CO}_{2}$ reuse. Chemical 28 Engineering Journal. 219: 96-108. 
1 [35] Ng, K.S., Zhang, N., Sadhukhan, J., 2012. Decarbonised coal energy system

2 advancement through $\mathrm{CO} 2$ utilisation and polygeneration. Clean Technologies and

3 Environmental Policy. 14(3): 443-451.

4 [36] Ng, K.S., Martinez Hernandez, E., 2016. A systematic framework for energetic,

5 environmental and economic (3E) assessment and design of polygeneration systems.

6 Chemical Engineering Research and Design. 106: 1-25.

7 [37] Ng, D.K.S., Ng, K.S., Ng, R.T.L., 2017. Integrated biorefineries, in: Abraham, M.A.

8 (Eds.), Encyclopedia of Sustainable Technologies, Elsevier: Oxford. p. 299-314.

9 [38] Sadhukhan, J., Ng, K.S., Hernandez, E.M., 2014. Biorefineries and Chemical

10 Processes: Design, Integration and Sustainability Analysis. Wiley, Chichester.

11 [39] WRAP. 2020. National compositional estimates for local authority collected

12 household waste and recycling in the United Kingdom: national household waste

13 composition 2017, prepared by Eunomia Research \& Consulting Ltd.

14 https://wrap.org.uk/sites/files/wrap/National\%20household\%20waste\%20composition\%2020

$15 \quad \underline{17 . p d f}$ (accessed 3 April 2020).

16 [40] WRAP. 2009. A financial assessment of recycling mixed plastics in the UK. Report

17 prepared by Axion Consulting.

18 https://www.wrap.org.uk/sites/files/wrap/WRAP\%20A\%20financial\%20assessment\%20of\%

19 20recycling\%20mixed\%20plastics\%20in\%20the\%20UK.pdf (accessed 1 April 2020).

20 [41] Martinez Hernandez, E., Ng, K.S., 2018. Design of biorefinery systems for conversion of corn stover into biofuels using a biorefinery engineering framework. Clean Technologies and Environmental Policy. 20(7): 1501-1514.

23 [42] Ng, K.S., Martinez-Hernandez, E., 2020. Techno-economic assessment of an 24 integrated bio-oil steam reforming and hydrodeoxygenation system for polygeneration of 25 hydrogen, chemicals, and combined heat and power production, in: Ren, J., Y. Wang, C. He (Eds.), Towards Sustainable Chemical Processes, Elsevier: Oxford. p. 69-98. and material balances of SRF production process. Part 3: Solid recovered fuel produced from municipal solid waste. Waste Management \& Research. 33(2): 146-156. 
1 [44] Insideevs. 2017. Honda pays £10/kg (nearly \$13) for Clarity's hydrogen supplies in 2 UK. https://insideevs.com/news/333970/honda-pays-10-kg-nearly-13-for-claritys-hydrogen3 supplies-in-uk/. (accessed 18 May 2020)

4 